\title{
Ecological and financial strategies provide complementary benefits for smallholder climate resilience: insights from a simulation model
}

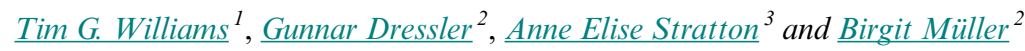

\begin{abstract}
Researchers and development organizations regularly grapple with competing ecological and financial strategies for building climate resilience in smallholder agricultural systems, but rarely are such approaches considered in tandem. Using a socialecological simulation model, we explored how different combinations of legume cover cropping, an ecological insurance, and indexbased crop insurance, a financial insurance, affect the climate resilience of mixed crop-livestock smallholder farmers over time. The model simulates interactions between soil nutrient dynamics, crop yields, and household wealth, which is carried solely in the form of livestock. We assume legume cover cropping provides biological nitrogen fixation, thereby increasing soil fertility and productivity over time, whereas microinsurance gives payouts in drought years that provide ex-post coping benefits. Our model results indicate that the benefits of cover cropping to mean household income strongly complement the shock-absorbing benefits of microinsurance. Specifically, we found: (1) insurance always provides larger benefits during and in the wake of a drought, while cover cropping progressively reduces poverty in the medium- to long-term; (2) the use of crop insurance solely as an ex-post coping strategy may not reduce the incidence of poverty; and (3) legume cover cropping offers larger relative benefits in more degraded environments and for poor farmers. These results underscore the complementary roles that ecological and financial strategies could play in building resilience in smallholder agricultural systems. The stylized model constitutes an important social-ecological foundation for future empirical research to inform agricultural innovation and sustainable development priorities.
\end{abstract}

Key Words: complementarity; legume cover cropping; microinsurance; resilience; simulation modeling; smallholder agriculture; socialecological systems

\section{INTRODUCTION}

How to support climate resilience in smallholder agricultural systems remains a topic of uncertainty and debate among researchers and development organizations (Hansen et al. 2019, Tomich et al. 2019a). Institutional interventions such as microinsurance schemes have recently gained traction as tools for agricultural development and poverty reduction in the Global South (Hazell et al. 2010, SwissRe 2013, Kramer et al. 2019). Simultaneously, there is an increasing drive for ecological intensification to sustain or enhance both livelihoods and natural resources (Bommarco et al. 2013, FAO 2018, HLPE 2019). Such financial and ecological strategies both act as a form of insurance by reducing risk in agricultural production, yet they function through distinct mechanisms: ecological insurance improves ecological functioning to stabilize and increase production over time, whereas financial insurance stabilizes agricultural income on a seasonal basis against climate shocks. Given these distinct mechanisms, ecological and financial strategies may provide benefits for smallholder systems that are heterogeneous both throughout the population and over time. Thus, when considered together, these disparate strategies may be complementary. To make progress toward sustainable development therefore requires an integrated perspective on the benefits of ecological and financial development strategies. We aim to provide a valuable contribution toward this goal by conducting a rigorous comparative assessment of how two particular ecological and financial strategies may affect smallholder climate resilience.

Microinsurance is a form of low-sum financial insurance specifically targeted at low-income households. In recent decades, it has gained traction in the international agricultural community as a resilience-enhancing strategy (SwissRe 2013, Müller et al. 2017, Kramer et al. 2019). By providing financial compensation during droughts, microinsurance directly builds the ex-post coping capacity (i.e., following the occurrence of a shock event) of smallholder households. Additionally, by reducing production risk, microinsurance can provide ex-ante benefits that enable riskaverse households to engage in different production activities and potentially escape poverty traps (Barrett et al. 2007, Carter et al. 2018). Index-based insurance, which gives payouts based on a predetermined climate index (e.g., rainfall) has been advocated as a tool for sustainable development because it helps to overcome some of the "moral hazard" issues associated with conventional indemnity-based insurance, i.e., the tendency for insured households to reduce their own risk management and increase costs for insurers (Hazell et al. 2010).

Farm management practices based on ecological principles take a different approach to smallholder climate resilience. By increasing ecosystem functions and diversity, they provide farmers a form of natural insurance (Finger and Buchmann 2015, Valente et al. 2019, Schaub et al. 2020). In particular, planting of nitrogen $(\mathrm{N})$-fixing leguminous cover crops to be incorporated into the soil as green manure builds resilience by increasing soil organic matter (SOM) and nutrient availability, which help to maintain or increase crop yields over time without other external inputs (Drinkwater et al. 1998, Snapp et al. 2005, Blanco-Canqui et al. 2012, Bommarco et al. 2013). Use of legume cover crops as green manures is receiving increasing attention (in the academic literature, from governments, and from non-profit and development organizations) as an approach for building smallholder resilience through conservation agriculture, 
regenerative agriculture, and agroecology (Florentín et al. 2011, Kaye and Quemada 2017, Wittwer et al. 2017, FAO 2018, HLPE 2019).

Despite their benefits, both microinsurance and legume cover cropping exhibit potential tradeoffs that may affect their relative performance. For example, insurance often does not incentivize sustainable management practices (O'Connor 2013) and may even lead to maladaptive outcomes in socio-environmental systems (Müller et al. 2017). In contrast, adopting legume cover cropping may lead to short-term losses in labor or yields as farmers transition to new management practices and build soil fertility (Martini et al. 2004). The structure of the payouts that these strategies provide may also contribute to divergent effects; although both entail annual costs, the ex-post benefits of index-based microinsurance are only experienced during shock years in which the index is triggered, whereas cover cropping provides a more consistent, though likely smaller, economic benefit (Rosa-Schleich et al. 2019). When considered together, it is therefore possible that microinsurance and cover cropping provide complementary benefits (Hansen et al. 2019).

However, it remains a challenge to understand the conditions (i.e., when, where, and for whom) under which each of these strategies may be most beneficial to smallholder climate resilience. A deeper understanding of their benefits can help to inform and target agricultural research and development and contribute to the debate on the relative merits of financial and ecological development approaches (Tomich et al. 2019b). Given the nascence of research on the impacts of both microinsurance and legume cover cropping on the global agricultural stage, observational datasets do not exist to evaluate their relative or complementary effects. In addition, both strategies involve feedbacks between household assets and underlying ecological systems, necessitating an integrated socialecological perspective.

Process-based simulation models are powerful tools for extending the understanding of these relationships and feedbacks beyond existing empirical datasets, as well as exploring changes in conditions and processes that would be impossible to control for in the field (Magliocca et al. 2013). Simulation models that combine social and ecological processes (henceforth social-ecological simulation models) have been extensively used to explore questions related to resilience and smallholder agricultural livelihoods (Kremmydas et al. 2018, Dressler et al. 2019, Egli et al. 2019). In the context of microinsurance, an agent-based model (ABM) was used to show that there can exist long-term maladaptive feedbacks related to livestock insurance in pastoral systems (John et al. 2019). Models incorporating soil nutrient dynamics have shown that access to credit, fertilizer, and improved seeds can help to reduce poverty but does not guarantee long-term social-ecological sustainability (Schreinemachers et al. 2007). Process-based models have been used to explore the effects of different policies to mitigate $\mathrm{N}$ losses (Kaye-Blake et al. 2019) and to assess the emergence of poverty traps (Stephens et al. 2012). However, despite the suitability of social-ecological simulation models to investigate short-and long-term tradeoffs and to compare disparate resilienceenhancing strategies across a population, such temporal and distributional effects are rarely studied (Williams et al. 2020).

For this study, we developed a household-level, social-ecological simulation model of a mixed crop-livestock smallholder agricultural system. Rather than being calibrated to a specific location, the model was purposely stylized and represented the general characteristics of many mixed crop-livestock systems in the Global South. As such, the model is intended as a tool for generating hypotheses to be empirically tested by researchers in specific contexts, as well as for illustrating key social-ecological dynamics relevant for informing future interventions, programs, or public policy directed at poverty alleviation.

Using the model, we address the following questions:

1. What are the relative effects of planting legume cover crops as green manure and index-based crop insurance on smallholder households' climate resilience?

2. Are there short- and long-term complementarities in these effects?

3. How do these strategies differentially affect rich and poor households?

In answering these questions, we operationalized the concept of resilience using measures of household wealth and income. In the model, these economic measures were mediated by ecological capital (i.e., soil nutrients). Our perspective is therefore an ecological-economic one. We hypothesized that financial insurance provided greater benefits to resilience in the short-term, but that over time the benefits of cover cropping for SOM would provide equal or superior resilience benefits. Thus, when applied together, the strategies will demonstrate complementarity over time. Additionally, because cover cropping constitutes a progressive ecological adaptation of the agroecosystem, we expected its benefit to be strongest for poor households with degraded soil fertility.

\section{METHODS}

Our model description generally follows the Overview, Design Concepts, Details, and Decisions $(\mathrm{ODD}+\mathrm{D})$ format (Müller et al. 2013). We provide the full protocol in Appendix 1. The model was implemented in Python and code is available at CoMSES.net (refer to Data Availability Statement).

\section{Model purpose}

The social-ecological simulation model was developed to investigate climate resilience in smallholder mixed crop-livestock systems, which are prevalent in many dryland regions in the Global South, in which crop growth is limited by rainfall (Powell et al. 2004, Thornton and Herrero 2015). To more easily disentangle the key social-ecological dynamics, we sought to limit model complicatedness (Sun et al. 2016). As such, the model does not draw from extensive empirical data to represent a specific location, but we draw several parameters from Ethiopian data sources to define the relative scales of model elements (e.g., crop and livestock prices). We affectionately named the model SMASH: Stylized Model of Agricultural Smallholder Households.

Our model analysis examined the general mechanisms through which selected household-level adaptation strategies affect climate resilience. Because of the model's stylized nature, we did not seek to directly generate policy-relevant recommendations through the model analysis. Rather, our assessment intends to (1) generate hypotheses that can be tested by researchers in future empirical studies and (2) provide theoretical grounding for future 
agricultural development and poverty reduction programs to integrate ecological and economic adaptation strategies.

\section{Entities, state variables, and scales}

The model (Fig. 1) represents a population of smallholder households that engage in agriculture and carry wealth solely in the form of livestock. Each household is defined by static land holdings and consumption requirements and has dynamic income and wealth. Livestock are grazed on a combination of on-farm crop residues and an external rangeland, which is not explicitly modeled. Each household's land (or "field") has an evolving level of organic and inorganic nutrients, the dynamics of which influence crop yields. The model is spatially implicit, no environmental feedbacks beyond the household scale are represented, and households do not interact.

Fig. 1. Conceptual diagram of the stylized model of agricultural smallholder households (SMASH) showing the main interactions. Triangles pointing inward (/outward) indicate points at which nutrients are added to (/lost from) the system.

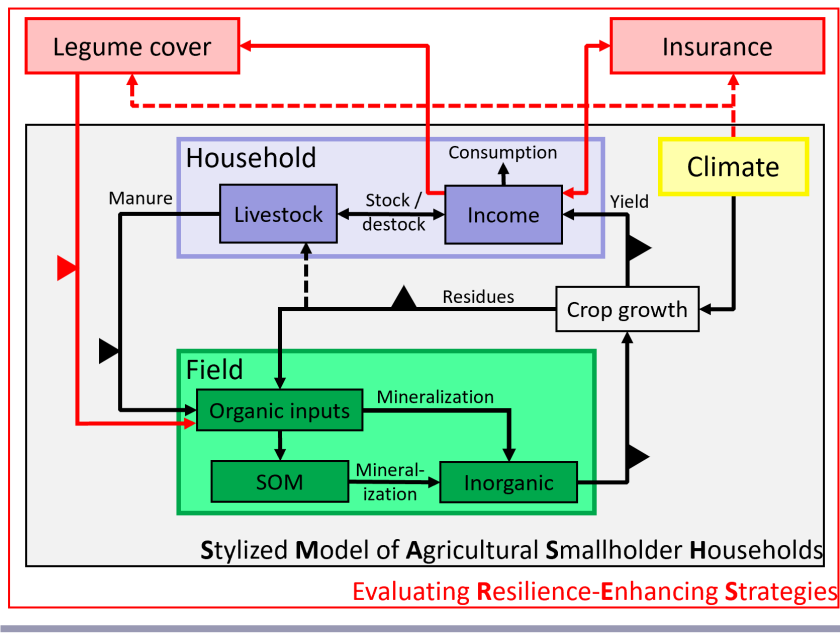

\section{Process descriptions}

The model operates at an annual time step. Each year of the simulation involves calculation of (1) soil nutrient flows, (2) crop yields, and (3) household income and wealth.

\section{Nutrient dynamics}

The model represents two pools of soil nutrients: organic and inorganic. The organic pool represents SOM and soil organic N together in a stylized manner, with fluxes primarily corresponding to the organic N portion of SOM. Although crop yields are also limited by other nutrients, we focused on $\mathrm{N}$ because it is generally the most limiting nutrient for crop growth (Robertson and Vitousek 2009). We henceforth refer to this pool as SOM, though we note that we quantify it using $\mathrm{kg} \mathrm{N} / \mathrm{ha}$ rather than as a percentage of bulk soil. Each year, inorganic nutrients are mineralized from both added organic matter and from the SOM pool (Fig. 1). These inorganic nutrients are available to that year's food crop.

There are several points at which nutrients enter and leave the system (Fig. 1). First, a fraction of the mineralized nutrients is lost through leaching. This fraction is higher with lower levels of
SOM (Drinkwater et al. 1998, Bommarco et al. 2013). Second, all nutrients contained in the harvested component of the crop are exported from the modeled system. Third, $10 \%$ of the crop residues are assumed to be lost or removed (Assefa et al. 2013). Nutrients enter the system through livestock manure, which qualitatively represents nutrient import from external grazing land. Hence, households with larger livestock herds have larger SOM additions, and consistent cropping with no replenishment of SOM will slowly degrade soil fertility over time (Reeves 1997).

In many mixed crop-livestock systems, households apply inorganic fertilizers to supplement in-soil nutrients for crop growth. However, inorganic fertilizer was not included in this version of the model. Including fertilizer would require additional assumptions about household decision making related to fertilizer use and livestock nutrient management, as well as complicate the model dynamics. We interpreted our results in light of this assumption.

\section{Climate and crop yields}

We modeled crop yields using the yield gap concept, in which yields are reduced from a maximum potential value through water and/or nutrient limitations (Tittonell and Giller 2013). We first simulated the regional climate condition, which was the same over all households and was independently sampled each year from a normal distribution. Using this, we calculated field-level water reduction factors. Here, field-level SOM helps to reduce drought sensitivity (Bommarco et al. 2013). Next, if the available fieldlevel inorganic $\mathrm{N}$ was insufficient to produce this waterconstrained yield, production was limited by the available inorganic N. Finally, the resulting value was perturbed by a fieldlevel, normally distributed stochastic error term. This term conceptually represents all uncontrollable factors affecting crop yields and other positive or negative household-level shocks, as well as local variability in the observed climate conditions within a region containing a population of smallholder households.

\section{Household income and wealth}

The model makes several assumptions with respect to household income and wealth. First, households do not have access to financial savings and instead use livestock as a bank account. Hence, wealth and livestock are equivalent in the model. Second, we do not consider non-farm employment markets. Third, households cannot purchase fodder for their livestock under baseline conditions, making livestock a risky wealth stock. These conditions are characteristic of many mixed crop-livestock systems in the Global South (Powell et al. 2004, Thornton and Herrero 2015), in which livestock are the primary savings mechanism. We interpreted our results in the light of these assumptions.

Households have a fixed annual consumption requirement. They earn income solely from harvested crops, which are sold each year at a constant price. If net income is in surplus, households add to their wealth stores by purchasing livestock. If net income is in deficit, households sell the required amount of livestock as a coping measure (Bellemare and Barrett 2006, Moyo and Swanepoel 2010). If income is in deficit and the household has no available wealth stores, we assume that they can perfectly reduce their consumption (i.e., wealth cannot be negative, and households do not exit the modeled system). Finally, we do not model livestock reproduction or mortality. 
The ability for households to accumulate wealth is constrained by fodder availability for livestock (Valbuena et al. 2012, Assefa et al. 2013); we assume that a fixed percentage of livestock feed requirements must come from on-farm crop residues and that households cannot keep livestock that they cannot feed. Hence, households with larger land area (i.e., producing a greater quantity of crop residue) have larger wealth capacities. Additionally, this implies that in a year of complete crop failure, households lose all livestock that were dependent on crop residues.

\section{Feedback loops}

The structure of the model implies the existence of a feedback loop; surplus income enables accumulation of livestock, providing additional organic matter, which both decreases drought sensitivity and increases future crop yields and income. A household's ability to experience this positive feedback cycle is mediated by a combination of random and non-random factors; households' attributes such as land endowment and SOM determine their wealth-generating ability and hence predispose them to certain trajectories. In addition, stochasticity through household-level random yield effects introduces a degree of path dependence into the model; a household that is unlucky one year (i.e., has a large, negative random effect in their crop yields) may be pushed into a poverty trap (Tittonell 2014, Haider et al. 2018) with decreasing livestock herds, SOM, crop yields, and income.

\section{Calibration and specification of household types}

Given our interest in exploring the distributional effects of resilience strategies, we specified the model with three types of households that differ exclusively in their land endowment. We referred to these types as: land-poor, middle, and land-rich. We used pattern-oriented modeling (POM; Grimm et al. 2005) to estimate values for unknown model parameters that lead to a set of desired emergent model behaviors. To qualitatively represent both chronic and transitory poverty dynamics (Barrett 2005), we selected baseline parameters such that the land-poor households were "always poor" (i.e., never maintain positive levels of wealth throughout the simulation), the middle households were "sometimes poor," and the land-rich households were "never poor". Additionally, we required that SOM never increased to a maximum value under baseline conditions and that the middle households could recover from shocks. See further details in Appendix 1.

\section{Resilience-enhancing strategies}

We represented both microinsurance and legume cover cropping in the model as scenarios, rather than as an outcome of an explicit decision-making process. Thus, we did not focus on the question of "how" to expand the use of these strategies. Instead, we explored what the potential benefits might be "if" each strategy is taken up, when these benefits may be experienced, and by whom. We therefore assumed that households always engaged in a given strategy, regardless of their previous experiences or wealth.

We included a representation of index-based crop insurance. A household with insurance must pay an annual premium to participate and receives a payout in any year that the climate condition is below a pre-specified threshold (e.g., the $10^{\text {th }}$ percentile). The payout rate is the same for all households and is equivalent to the crop yield under average climate conditions, assuming a nutrient limitation factor of 0.5 . Insurance payouts supplement the households' income and, in contrast to regular income, can be used to buy fodder for livestock. Thus, the insurance de-risks the wealth stock and represents a form of asset protection rather than replacement (Carter et al. 2018). Because we did not model fertilizer or other agricultural production investments, we considered only the ex-post coping effects of microinsurance and not its ex-ante risk-reducing benefits.

Legume cover crops are grown in the fallow season and incorporated into the soil as green manures. Through biological $\mathrm{N}_{2}$ fixation and production of high- $\mathrm{N}$ biomass, green manures provide additional organic $\mathrm{N}$ inputs to the soil. Livestock are not grazed on the cover crops. We assume that the cover crops' growth declines under adverse rainfall conditions in the same way as crop yields; thus, in a year with no rainfall, cover crops fail and no $\mathrm{N}$ is fixed (Serraj et al. 1999). We assumed an annual financial cost equal to the annual cost of insurance. By assuming that the labor required for cover cropping would otherwise be applied to other income-generating activities, this financial proxy for labor is appropriate.

\section{Outcome measures: poverty reduction and shock absorption}

We operationalized climate resilience in two distinct ways. We conceptualized both of these as nested within "development resilience," which describes "the capacity over time...to avoid poverty in the face of various stressors and in the wake of myriad shocks" (Barrett and Constas 2014). The first measure represents the longer-term capacity of households to avoid poverty (i.e., retain positive livestock holdings) in the presence of climate variability and evolving SOM levels.

We referred to this resilience measure as the "poverty-reducing" capacity, $R^{\text {pov }}$ :

$$
R^{\text {pov }}=P\left(\text { wealth }_{t=T_{\text {pov }}}>0\right)
$$

where the probability is evaluated over 300 model replications at time $T_{p o v}$ (e.g., $T_{p o v}=50$ years). We conducted a convergence analysis to determine the appropriate number of model replications that ensured our estimates were not strongly influenced by model stochasticity (Appendix 2).

To compare a household's poverty-reducing capacity under cover cropping $(C C)$ and insurance (Ins), we calculated:

$$
P(C C>\text { Ins })^{p o v}=P\left(R_{C C}^{p o v}>R_{I n s}^{p o v}\right)
$$

where the $>$ sign is read as "is preferable to."

The second resilience measure assesses the shorter-term capacity of a household to maintain or increase its income in the wake of a drought. We referred to this as the "shock-absorbing" capacity, $R^{\text {shock }}$. Its measurement requires some explanation. First, we simulated the system under randomly generated climatic variability with a single-year "shock" (i.e., drought event) imposed in year $T_{\text {shock}}$. We measured the drought's severity by its percentile in the climate distribution. For example, a 5\% drought represents a 1 in 20-year event. The drought interacted with the model through its effect on food crop and cover crop yields in the same year, as well as any possible insurance payout (Fig. 1). This could have long-term implications if the household was required to sell livestock because this both reduces their future buffering capacity and reduces organic $\mathrm{N}$ inputs to their field. 
Table 1. Simulation parameters under each experiment.

\begin{tabular}{|c|c|c|c|c|c|c|c|c|c|}
\hline \multirow[t]{2}{*}{ Experiment } & \multirow[t]{2}{*}{$\mathrm{T}_{\text {pov }}$} & \multirow[t]{2}{*}{$\mathrm{T}_{\text {shock }}$} & \multirow[t]{2}{*}{$\mathrm{T}_{\text {assess }}$} & \multicolumn{2}{|c|}{ Cover crop } & \multicolumn{2}{|c|}{ Microinsurance } & \multirow[t]{2}{*}{ Complementarity } & \multirow{2}{*}{$\begin{array}{c}\text { Other } \\
\text { parameters }\end{array}$} \\
\hline & & & & $\begin{array}{c}\mathrm{N}_{2} \text { fixation } \\
(\mathrm{kg} \mathrm{N} / \mathrm{ha})\end{array}$ & Cost factor ${ }^{\dagger}$ & $\begin{array}{c}\% \text { of years } \\
\text { with } \\
\text { payout }\end{array}$ & Cost factor & & \\
\hline 1: shock absorption & - & $1-50$ & $1-15$ & $95^{\dagger}$ & 1 & 10 & 1 & Yes & Baseline \\
\hline 2: poverty reduction & 50 & - & - & $95^{\dagger}$ & 1 & 10 & 1 & Yes & Baseline \\
\hline $\begin{array}{l}\text { 3: strategy } \\
\text { characteristics }\end{array}$ & 20 & 10 & 3 & $40-200$ & $0.1-4$ & $1-30$ & $0.1-4$ & No & Baseline \\
\hline $\begin{array}{l}\text { 4: social- } \\
\text { environmental } \\
\text { characteristics } \$\end{array}$ & 50 & 20 & 5 & $95^{\dagger}$ & 1 & 10 & 1 & No & Varied \\
\hline \multicolumn{10}{|c|}{$\begin{array}{l}\text { Drawn from empirically measured values in temperate settings (Badgley et al. 2007). See Appendix 1, Figure A1.3. } \\
\text { This represents the annual cost of cover cropping relative to the baseline value for microinsurance. } \\
\text { \$ We used different } T_{\text {pov }} \text { and } T_{\text {assess }} \text { in this experiment for visual clarity in the plotting. We verified that this does not affect the shape of the relationships. } \\
\text { ' See Chantarat et al. (2017). }\end{array}$} \\
\hline
\end{tabular}

To investigate the temporal dynamics of the shock-absorbing capacity, we ran experiments that differed across two dimensions. The first dimension represents the point in time at which the shock occured in the simulation $\left(T_{\text {shock }}\right)$. Because both strategies (microinsurance and cover cropping) are applied in every year, $T_{\text {shock }}$ is equivalent to the amount of time the given strategy has been in use. The second dimension represents the period of time over which the effects of and recovery from the shock are assessed $\left(T_{\text {assess }}\right)$.

Thus, we calculated:

$$
R^{\text {shock }}=\sum_{t=T_{\text {shock }}}^{T_{\text {shock }}+T_{\text {assess }}} \text { income }_{t}
$$

To compare the shock-absorbing capacity of a household under the two strategies, we calculated:

$$
P(C C>\text { Ins })^{\text {shock }}=P\left(R_{C C}^{\text {shock }}>R_{\text {Ins }}^{\text {shock }}\right)
$$

To investigate complementarities between the two strategies, we compared the resilience outcomes with both strategies implemented together (i.e., the households engage in both microinsurance and cover cropping and paying the costs for both) against the outcomes of each strategy in isolation. We considered complementarity as a situation in which engaging in both strategies yielded additional benefits above that derived from engaging in one strategy alone (either cover cropping or microinsurance) and a tradeoff as a situation in which engaging in both strategies was less beneficial than engaging in a single strategy. Tradeoffs may occur, for example, if the benefits of adding microinsurance to complement cover cropping do not offset the increased cost for the insurance premiums.

For both measures of resilience, our focus on wealth and income may appear to represent solely economic outcomes and not ecological ones. However, because a household's wealth- and income-generating abilities are mediated over time by SOM, we indirectly incorporated ecological capital into our resilience measures. Additionally, through our dual resilience measurement, we combined stability properties with the ability to resist or undergo qualitative changes in structure (Holling 1973). Thus, a resilient household can both cope with drought-induced disturbance and resist entering a social-ecologically degraded "poor" state. However, because we did not focus on household decision-making or landscape-level processes, we did not consider facets of resilience related to adaptive responses or transformative system-level transitions (Folke 2016, Walker 2020).

\section{Simulation experiments}

We structured our analysis into four main experiments (Table 1). The first and second experiments respectively examined the shock-absorbing capacity $\left(R^{\text {shock}}\right)$ and the poverty-reducing capacity $\left(R^{\text {pov }}\right)$ of households under a range of time horizons. In these two experiments, we examined resilience under cover cropping and microinsurance, as well as with both strategies implemented together. In the third experiment, we tested how different assumptions about costs and benefits of the two strategies affected the resilience comparisons (i.e., $P(C C>I n s)^{\text {shock }}$ and $\left.P(C C>I n s)^{p o v}\right)$ to identify "robust regions" within the parameter space (Lempert 2002). Here, we systematically varied the annual costs of both microinsurance and cover cropping, the microinsurance "strike rate" (i.e., percent of years with a payout), and the amount of $\mathrm{N}$ fixed by the cover crops. When the microinsurance cost factor is one, the insurance is actuarially fair. A cost factor less than one represents subsidized insurance and a factor greater than one implies net profits to the insurer.

In the final experiment, we explored how the resilience comparisons changed under different socio-environmental conditions. To do this, we conducted a sensitivity analysis on the parameters of the model. We employed a meta-modeling approach for global sensitivity analysis (Iooss and Lemaître 2015) in which we first ran our model under a wide range of perturbed parameter configurations and then fit a non-parametric regression model to explain how both resilience assessments changed over the perturbed parameter space. From the metamodel, we constructed a measure of "partial dependence," which describes the relationship between each parameter and the resilience measures as assessed by the meta-model. We described this methodology in Appendix 3. 


\section{RESULTS}

\section{Model dynamics}

Before presenting the results of our main experiments, we first illustrate the representative behavior of the model under three simulations: baseline conditions with regular climate variability (Fig. 2A), in the wake of a drought (Fig. 2B), and with the two strategies (Fig. 2C). To most effectively demonstrate the relevant characteristics of the model, we assessed a different time period and different outcome measures in each representative simulation.

Fig. 2. Model dynamics under representative simulation runs. Part A shows the evolving wealth and soil organic matter (SOM) of the three household types under baseline conditions (i.e., without insurance or cover crops) and regular climate variability. Each line represents a single household. Birr is the Ethiopian currency. B shows the average effect of an imposed $10 \%$ shock in year 15 on the middle household type under baseline conditions. $\mathrm{C}$ shows the average effect of the two strategies on the middle household type under regular climate variability. The vertical lines in $\mathrm{C}$ indicate years in which insurance payouts are triggered.

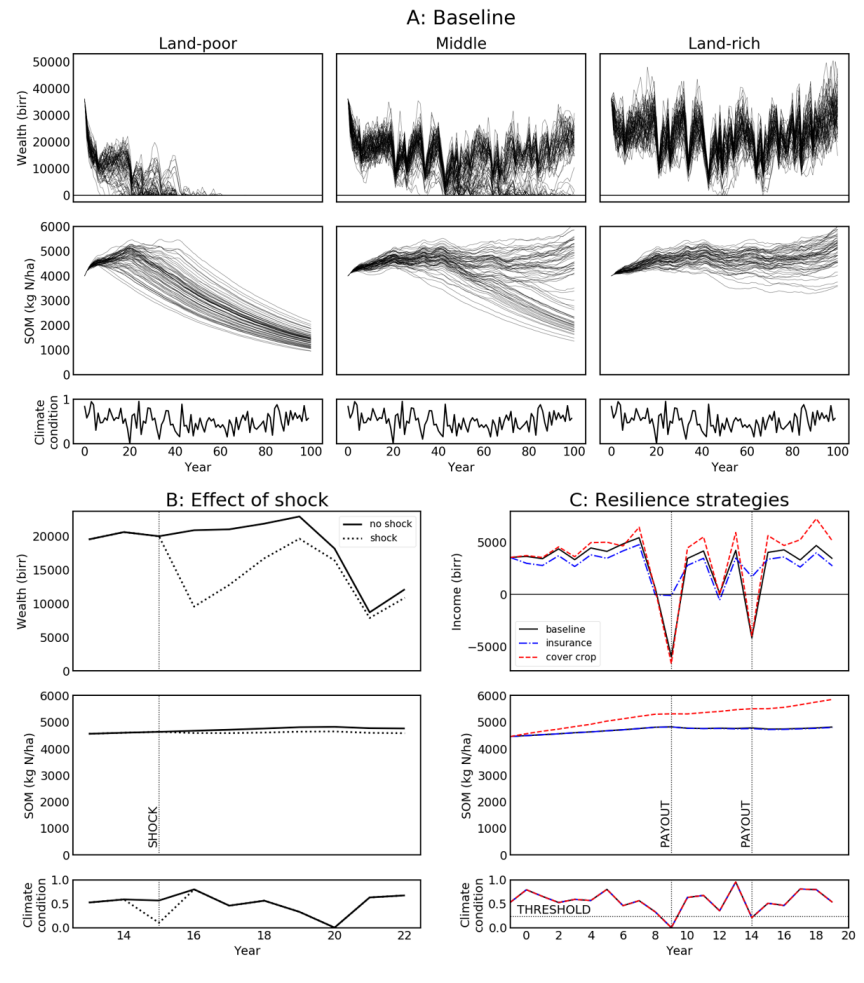

First, as specified by the calibration approach, under baseline conditions and regular climate variability, the land-poor households do not earn enough income to satisfy their consumption requirements and so always become poor (i.e., have zero wealth), whereas the middle households sometimes become poor and the land-rich households are never poor (Fig. 2A). The divergent outcomes for the middle households emphasize the path dependence in the model; all middle households begin the simulation in the same condition, but the randomness in the calculation of crop yields leads to divergent trajectories, particularly when droughts cause some households to either irrevocably lose their wealth reserves or to experience transitory poverty. Households with positive wealth reserves, through external nutrient input from livestock manure, are able to maintain their SOM, but SOM steadily declines for households with no wealth reserves (Fig. 2A). An imposed drought leads to a decline in wealth that persists for several years (Fig. 2B). Due to the wealth-SOM feedback in the model, this results in a marginally lower SOM than the drought-free counterfactual (Fig. 2B).

Microinsurance and cover cropping affect the model dynamics in several ways. Microinsurance premiums, which cost $10 \%$ of average yields, slightly decrease income under regular years, but the insurance payouts buffer the effects of drought when payouts are received (Fig. 2C). Cover cropping's benefit to income in general increases over time and is strongest in years with higher rainfall (Fig. 2C). These effects are due to the higher inorganic nutrient availability (from decomposition of cover crop residues) that reduces the extent to which nutrients inhibit crop yields. Because nutrient availability is more critical in high-rainfall years when water is not a constraining factor, the largest benefits are therefore experienced at these times.

\section{Shock absorption}

Our results conform with our main hypothesis, showing that insurance as an ex-post coping strategy is preferable in the shortterm recovery from a drought, but that there is a time at and beyond which cover cropping provides larger benefits (Fig. 3). This is not a single point, however, but a line of $\left(T_{\text {shock }}, \mathrm{T}_{\text {assess }}\right)$ pairs. When assessing the effects solely in the year of the shock $\left(T_{\text {assess }}=1\right)$, insurance is the preferable strategy (i.e., $P(C C>\operatorname{Ins})$ $<0.5)$ in $100 \%$ of the simulations over all time. After 15 years of legume cover cropping, it takes approximately 5 years following a shock for the cumulative benefits of cover crops to outweigh the benefit of the insurance payout (i.e., transition to red in Fig. 3 ). After 25 years of cover cropping, this decreases to 3 . These effects are qualitatively consistent for each of the three household types (Appendix 4, Fig. A4.3), showing that all types of households strongly benefit from insurance in the wake of a shock. However, when the drought is not severe enough to trigger an insurance payout, cover cropping consistently provides superior shock absorption benefits (Appendix 4, Fig. A4.4).

Because of the strong power of microinsurance in buffering the effects of drought, adding microinsurance to complement cover cropping always increases shock-absorbing capacity (Fig. 4A). In contrast, adding cover cropping to complement microinsurance leads to tradeoffs in the short-term (black region in Figure 4B). This is for two reasons. First, in the year of the drought (i.e., $T_{\text {assess }}$ $=1$ ), crop yields are constrained by water availability rather than nutrient availability, so cover cropping provides little or no direct benefit to offset its costs. Second, it takes time for cover cropping to build SOM and, consequently, the water retention capacity of the soil. Thus, tradeoffs are stronger when $T_{\text {shock }}$ is lower. Nevertheless, as the amount of time for which cover cropping is practiced increases (i.e., as $T_{\text {shock }}$ increases), its direct benefits to water retention enabled through higher SOM lead to complementary effects even in the year of the shock (Fig. 4B). Similarly, as $T_{\text {assess }}$ increases, cover cropping provides progressively larger benefits that lead to long-term 
complementarity. Additional experimentation reveals that the long-term benefits of microinsurance and legume cover crops are greater than the sum of both strategies in isolation, i.e., they are synergistic (Appendix 5).

Fig. 3. Comparison of strategies' shock-absorption benefits. Probability that cover cropping provides larger benefits to shock absorption $\left(\mathrm{P}(\mathrm{CC}>\mathrm{Ins})^{\text {shock }}\right)$ as a function of the year at which the shock occurs $\left(\mathrm{T}_{\text {shock }}\right)$ and the number of years over which the effects are assessed $\left(\mathrm{T}_{\text {assess }}\right)$. Red areas represent situations in which cover cropping provides larger benefits than microinsurance. This shows the outputs for a middle household (i.e., "sometimes-poor"). The outputs for other household types were qualitatively consistent and are shown in Appendix 4.

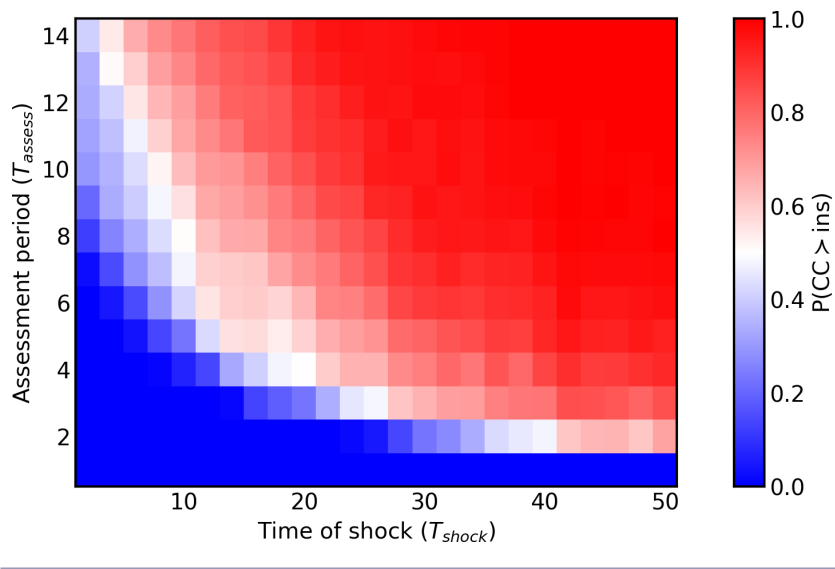

Fig. 4. Complementarity of strategies for shock absorption. Probability that implementing both strategies together provides greater shock absorption benefit than (A) cover cropping in isolation and (B) insurance in isolation. Green areas indicate complementarity, black indicates tradeoff.

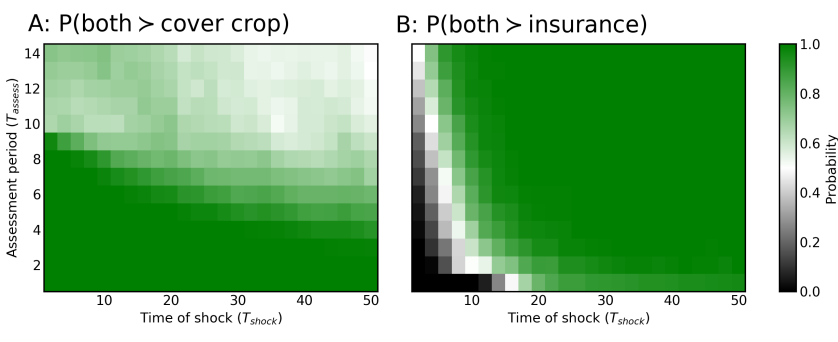

\section{Poverty reduction}

Under regular climate variability, legume cover cropping reduces poverty (Fig. 5). The effect is strongest for the land-poor households, who after 50 years of cover cropping are $21 \%$ more likely to avoid poverty. For the middle households, cover cropping almost eliminates poverty altogether. These strong effects are explained by the ecological feedback that cover cropping enables; higher SOM increases the productive ability of the households, thus increasing income over time (Appendix 4, Fig. A4.1A). However, there is a one- to two-year period in which the costs of cover cropping outweigh the benefits, resulting in decreased income for all household types (Appendix 4, Fig. A4.1A).
The results show a very different effect for insurance; for both the land-poor and middle households, insurance (modeled with expost coping benefits only) is not effective as a poverty alleviation mechanism (Fig. 5). Despite reducing income variability, the lower mean income in non-drought years because of required insurance premium payments leads to lower mean levels of wealth and SOM (Appendix 4, Fig. A4.1). This demonstrates that although the insurance scheme is actuarially fair, the required premium payments can enable an ecological feedback in the model whereby the payouts in shock years do not adequately compensate the income losses in regular years.

With respect to complementarity, for both land-poor and middle households, adding cover cropping to complement microinsurance successfully reduces poverty (Fig. 5). However, particularly for the land-poor households, the converse is not true; adding microinsurance to complement cover cropping increases poverty above the levels seen with cover cropping by itself. Hence, under the conditions of the model, increasing mean incomes, in this case, through cover cropping, is a more effective strategy for poverty alleviation than reducing income variability.

The measure of poverty reduction assessed in Figure 5 is not relevant for the land-rich households because they are not at risk of poverty under baseline conditions. Supplementary experimentation reveals that, in contrast to land-poor and middle households, microinsurance enables a positive ecological feedback with higher levels of wealth and SOM (Appendix 4, Fig. A4.1). Thus, households not vulnerable to poverty derive some benefit from the reduced income variability provided by microinsurance. To examine this more deeply for a land-rich household, in Appendix 6 we assessed the strategies' effects on a measure of risk-averse utility. Over a range of levels of risk aversion, microinsurance provides welfare benefits to land-rich households. This benefit is initially greater than that of cover cropping, but over time cover cropping's utility benefit surpasses microinsurance's.

\section{Influence of insurance and cover crop characteristics}

The superiority of microinsurance for shock absorption is robust to changes in the assumed strategy characteristics (Figs. 6B, 6D). When evaluating shock absorption over a three-year recovery period, insurance provides on-par or superior benefits to cover cropping up to cost factors of around two (i.e., a case in which the annual premium is twice the expected annual payout). Cover crops would need to be both freely available through household production (i.e., cost factor of zero) and fix very high levels of $\mathrm{N}$ to provide benefits equivalent to insurance (top-left of Fig. 6B). When effects are assessed only during the year of the shock (i.e., $T_{\text {assess }}=1$ ), insurance remains strongly preferable for shock absorption under all conditions in which a payout is received (Appendix 4, Fig. A4.5).

The superiority of cover crops for poverty reduction is also robust (Figs. 6A, 6C). Only at high cover cropping costs and low $\mathrm{N}_{2}$ fixation rates does insurance become preferable (Fig. 6A). Similarly, the cost factor for microinsurance generally has to be lower than one for it to reduce poverty more than cover cropping (Fig. 6C). Interestingly, more frequent microinsurance payouts appear to provide better poverty reduction benefits (top-left of Fig. 6C). Additional experimentation with the microinsurance payout frequency revealed a tradeoff: providing more regular 
Fig. 5. The effects of the ecological and financial strategies on poverty reduction. $\mathrm{P}($ wealth $>0)$ represents the probability that a household has positive wealth reserves. This probability was calculated for each household type at each time step as the average household poverty status across all simulation replications. We ran a 10-year burn-in period before implementing the strategies to reduce the sensitivity to initial wealth levels.
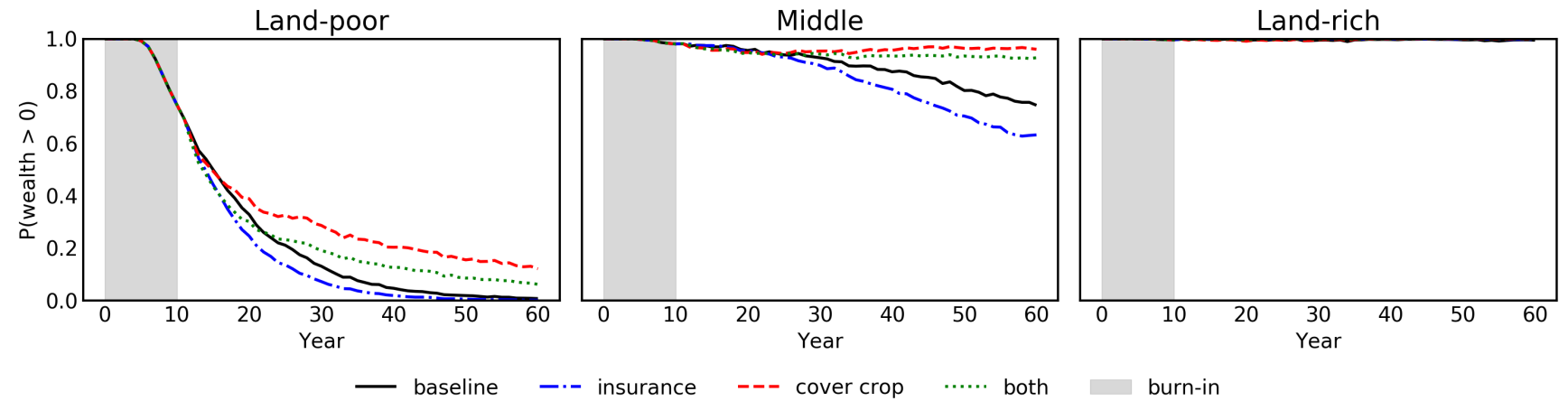

payouts effectively buffers income losses from moderate shocks but requires a higher annual premium that leads to increased vulnerability during more extreme shocks even when payouts are received (Appendix 7).

Fig. 6. Influence of ecological and financial strategy characteristics on the resilience comparisons. The black dots represent the baseline settings used in other experiments. For cover cropping (A and B), the cost factor represents the annual cost of cover cropping relative to the baseline annual cost of insurance. For insurance (C and D), the cost factor represents the ratio of the annual premium to the expected annual payout. When this equals one, the insurance is actuarially fair. The vertical axis for insurance represents the percent of years in which an insurance payout is received. In all cases, we show only the results for the middle household type; additional results are shown in Appendix 4, Figure A4.5 and Figure A4.6.
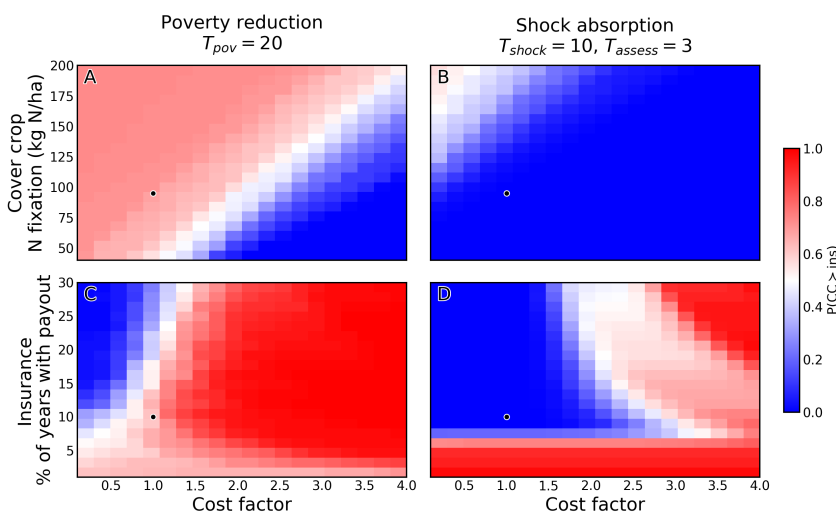

\section{Sensitivity to socio-environmental characteristics}

We use the sensitivity analysis (Fig. 7) both to assess the sensitivity of the model to its parameters and to draw insights about which resilience-enhancing strategy may be more preferable in different socio-environmental contexts. In Figure 7, the slopes of the lines give an indication of the magnitude and direction of the sensitivity of the $P(C C>$ Ins $)$ assessments for each parameter. Because this was generated under a single set of settings for $T_{\text {assess }}, T_{\text {shock }}$, and $T_{\text {pov }}$ (Table 1), in this section we are more interested in the slopes of the lines than the absolute $P(C C>$ Ins $)$ values.

As consumption requirements (i.e., household living costs) are increased in the model, cover cropping becomes a better strategy for poverty reduction (i.e., the dashed line is upward sloping in Fig. 7A). This complements the results of Figure 5; higher consumption requirements result in more households becoming poor (Appendix 4, Fig. A4.7A), thus accentuating the povertyreducing effects of cover cropping and further demonstrating cover cropping's pro-poor benefits. Other household-level parameters do not exert considerable influence on the comparisons (Figs. 7B, 7C), and this low sensitivity provides strength to our results in the above sections.

Changes to the average climate condition have divergent and nonlinear effects on the resilience strategy comparisons (Fig. 7D). Cover cropping provides the largest relative poverty reduction at moderate climate conditions. This is because under low climate conditions (i.e., low rainfall), cover crops fix less $\mathrm{N}$ and so do not provide long-term SOM benefits (Appendix 4, Fig. A4.7B), reducing their relative ability as a poverty reduction strategy. Conversely, with high climate conditions (i.e., more rainfall), more households have livestock and so are able to maintain SOM in their fields without cover crops (Appendix 4, Fig. A4.7B), also reducing cover crops' relative poverty reduction effect. For shock absorption, microinsurance is more beneficial than cover cropping under drier conditions (i.e., lower climate mean). Here, cover cropping more effectively buffers shocks under conditions of higher average rainfall because of SOM stabilizing yields during the more moderate shocks.

Under higher climate variability, cover cropping provides larger relative benefits to resilience (Fig. 7E). This is because cover cropping, through building of SOM, moderates the relationship between climate variability and yield variability. Although microinsurance provides payouts when climate conditions fall below the threshold, it does not buffer against climatic variability in non-payout years. Thus, when climate variability is higher, microinsurance has a lower relative benefit on average. 
Fig. 7. Sensitivity of the resilience assessments to changes in model parameters. "x" marks indicate the default parameter values used in the other experiments. Uncertainty bands represent $95 \%$ confidence intervals from 100 bootstrapped replications of the model outputs. The method used to generate these plots is described in Appendix 3. The regional climate variable characteristically represents the combined effect of water and temperature on crop yields, where a value of 1 indicates no climate-induced crop yield stress. We plot only four land parameters, which were selected based on sensitivity and social-ecological relevance.

HOUSEHOLD

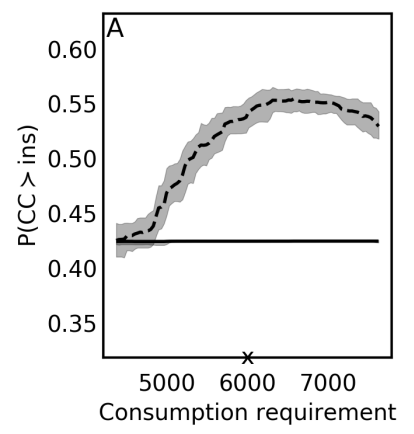

LAND

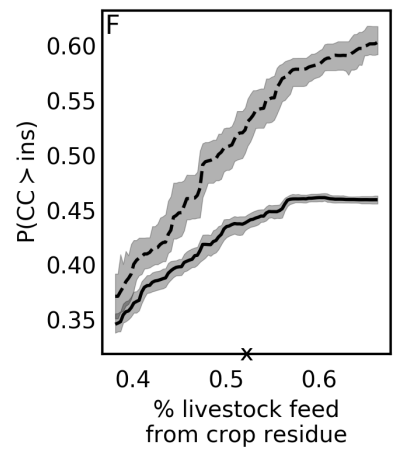

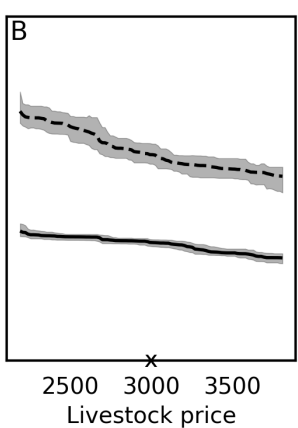

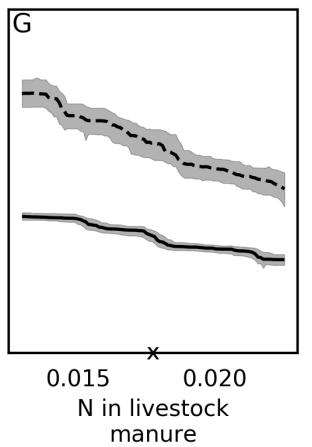

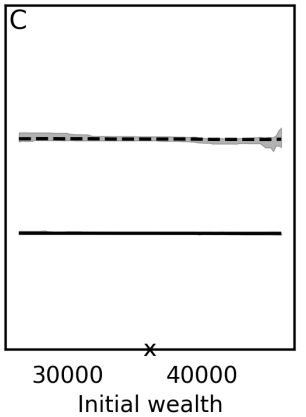

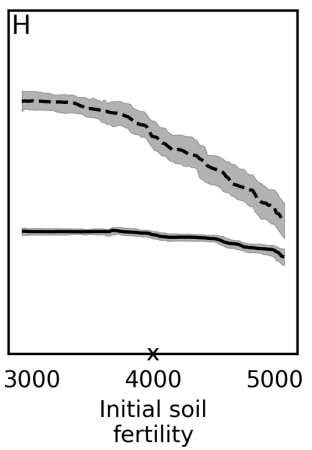

\section{CLIMATE}
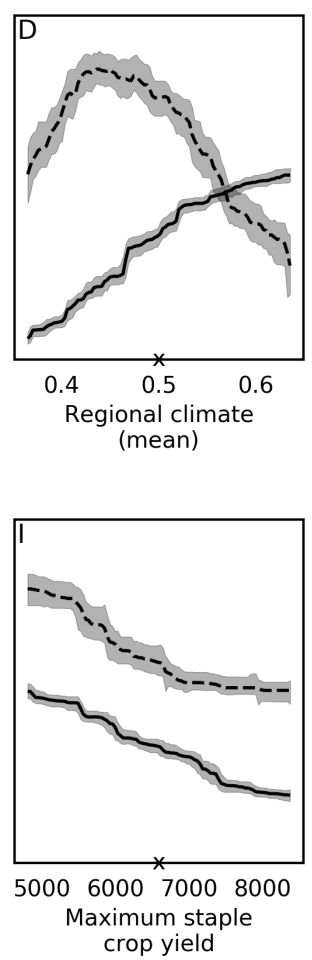

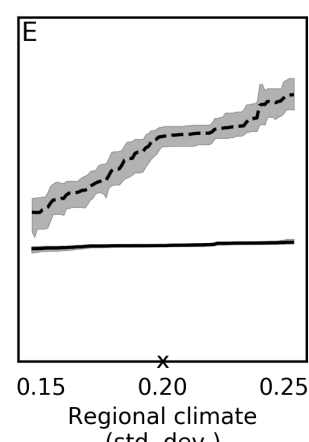

(std. dev.)
Cover cropping offers larger relative benefits to resilience under more adverse land characteristics, including situations with low external rangeland availability (Fig. 7F), low soil fertility returns from livestock (Fig. 7G), low soil fertility (Fig. 7H), and low yield potential (Fig. 7I). This result is not surprising because cover cropping progressively builds the system's natural capital. Relationships are qualitatively consistent between the two resilience measures.

\section{DISCUSSION}

\section{Microinsurance alone may not reduce poverty}

Our results suggest that, when used solely as an ex-post risk coping strategy, microinsurance alone may not help households to escape poverty (Figs. 5, 6). The premium payments required for microinsurance pushed poor households into poverty traps, thereby increasing poverty relative to baseline conditions. The lack of benefit for poor households highlights potential concerns regarding equity (Fisher et al. 2019) and is in accordance with some empirical research on index-based livestock insurance (Chantarat et al. 2017). In addition, we found that the vulnerable non-poor (i.e., middle) households also experienced higher poverty levels with the insurance alone. In part, this result is explained by our exclusion of ex-ante effects of insurance that would enable risk-averse households to engage in higher productivity livelihood activities, e.g., fertilizer use, crop choice, and other drought management strategies (Müller et al. 2011, Mobarak and Rosenzweig 2013, Karlan et al. 2014, Cole et al. 2017, Kramer et al. 2019). Inclusion of these effects may change the outcomes for the middle households. Nevertheless, the potential for microinsurance to cause vulnerable non-poor households to enter (transitory or chronic) poverty warrants further consideration in models with more complex household behavioral representations, including issues of moral hazard and interaction with other behavioral adaptations (O'Hare et al. 2016), as well as empirical investigation in different socioenvironmental contexts.

\section{Ecologically based farm management enhances resilience over time}

The robustness of the relative benefit of legume cover cropping for poverty reduction in our model is largely because of its 
assumed long-term benefits for agricultural productivity, which enable poor households to "step up" out of poverty (Dorward 2009). Other production technologies, such as improved crop varieties, cropping system diversification, irrigation, or conservation agriculture practices, may offer similar risk- and productivity-related benefits to cover cropping (Lin 2011, Hansen et al. 2019). Additionally, other studies have argued for fertilizer subsidies to break soil quality poverty traps (Barrett and Bevis 2015). Future research could evaluate and compare the resilience effects of such productivity-enhancing technologies and policies.

However, our analysis highlights the value of an integrated socialecological perspective. Our results show that legume cover cropping, i.e., investing directly in soil fertility itself, offers substantial combined potential for long-term environmental improvement and poverty reduction for smallholder farms, which may not exist with non-ecological technologies like inorganic fertilizer. Beyond the modeled effects, ecologically based management strategies offer numerous benefits to field- and landscape-level ecosystem services (Bommarco et al. 2013, Dainese et al. 2019), as well as reduce dependence on external inputs (Shennan 2008). Reduced externalities and ancillary benefits may be difficult to quantify and slow to build, but ultimately contribute to social-ecological synergies and resilience of a more "general" nature than the "specified" version assessed by our model (Cabell and Oelofse 2012, Jacobi et al. 2018, Stratton et al. 2020, Weise et al. 2020). Thus, we recommend that future policies, projects, and programs for smallholder poverty reduction empirically examine the benefits of integrated ecological and economic approaches (Müller and Kreuer 2016, Beck et al. 2019).

Our results revealed a one- to two-year period before cover cropping provided net benefits, i.e., a transition period (Martini et al. 2004, Lamine and Bellon 2009, Stratton et al. 2021). We did not focus on decision making or barriers to cover cropping adoption, but these results highlight that liquidity constraints and large time discounting rates could make households unable or unwilling to forgo these short-term losses to engage in cover cropping or similar practices (Quaas et al. 2019). Thus, a longterm view may not be pragmatic if focusing exclusively on cover crops. Capacity building, educational opportunities, and subsidies for cover crop seeds and labor during the transition period may help to overcome this barrier (Baumgärtner and Quaas 2010, DeLonge et al. 2016, Duff et al. 2017). Integration of dynamic decision making and interactions with other institutional structures are avenues for future research on ecological resilience-enhancing strategies.

\section{Harnessing ecological and financial complementarities for climate resilience}

Our results illustrate the strong complementarity of microinsurance and cover cropping: when implemented together, the strategies can provide greater benefit than either in isolation (Fig. 4). Climate resilience and poverty reduction programs, development agendas, and empirical studies could further test this complementarity and investigate bundling of adaptation strategies (Kramer and Ceballos 2018, Kramer et al. 2019, Wong et al. 2020). Our study demonstrates the promise of simulation models, whether empirically calibrated to specific locations or stylized as in this study, as tools for ex-ante examination of resilience dynamics and interactions between strategies over long timescales. Particularly in situations in which empirical evidence is lacking, simulation modeling can provide important information about time lags, barriers to adoption, and required investments, which can help to inform the design of poverty reduction programs and aid allocation.

Different types of households may require different forms of intervention; our results showed that chronically poor (i.e., landpoor) households benefited greatly from the ecological strategy of cover cropping, which acted as a necessary "cargo net" to mitigate risk and increase asset bases (Barrett 2005), but that adding microinsurance to complement cover cropping did not provide complementary poverty reduction benefits (Fig. 5). Thus, risk mitigation strategies such as cover cropping could be emphasized for enabling chronically poor households to step up out of poverty. However, because cover cropping alone did not bring all land-poor households out of poverty (Fig. 5), bundling with additional interventions, such as social protection measures (Hansen et al. 2019), may be necessary and should be investigated in future research. Bundled cover cropping and microinsurance appears to offer the greatest benefit for the vulnerable non-poor (i.e., middle) and non-poor (i.e., land-rich) households. For the middle households, the bundled strategies reduced poverty by a comparable amount to cover cropping in isolation (Fig. 5), as well as provided long-term complementarity in the wake of a drought (Fig. 4). For the land-rich households, particularly those with higher risk aversion, the bundled strategies provided immediate welfare improvements (Appendix 6).

Environmental context can exert additional influences on the appropriate combination of financial and farm-based strategies. For example, legume cover cropping had a comparative advantage in harsher and more degraded landscapes (Fig. 7). However, annual cover cropping may not be an appropriate agricultural practice in contexts with very low rainfall because this can limit potential biomass accumulation and $\mathrm{N}$ fixation, as well as potentially reduce soil moisture content and subsequent crop yields (Unger and Vigil 1998). In these contexts, drought-tolerant cover crops or other sustainable agriculture practices, such as mulching or agroforestry (Shankarnarayan et al. 1987, Ewansiha and Singh 2006, Bayala et al. 2012), may be more effective, both in isolation and in combination with insurance. Additionally, future case-based studies should target the insurance strike rate to the given social-ecological context (Lybbert and Carter 2015, Kramer et al. 2019) because context will affect climate-yield relationships, cover cropping performance, and poverty dynamics.

\section{Generalizability of our results}

We made several strong assumptions in our model that may influence the generalizability of our results. Most importantly, a critical component of our model is the wealth-based feedback loop in which wealth (livestock) directly fosters organic nutrient imports and improves crop productivity. In situations in which financial resources other than livestock are available (e.g., savings accounts), wealth would not be as strongly linked to field-level nutrient import. Additionally, large areas of grassland may be required to graze livestock to sustain nutrient applications on cropland, which might be infeasible given social-political constraints on land ownership and access (Dell'Angelo et al. 
2017). Furthermore, perfect import of nutrients from rangelands is an optimistic assumption because of competing uses for nutrients (Tittonell and Giller 2013, Berre et al. 2021). In all cases, the implication is that the wealth-based feedback loop in our model may be exaggerated and thus the strategies' effects on poverty overestimated. However, this exaggeration is the same under each strategy, so by focusing on the relative benefits of the two strategies, we reduced (though did not eliminate) the implications of this bias for our assessment.

Our modeled system most closely approximates an isolated rural community in which non-farm employment opportunities do not exist, use of fertilizer is low, and wealth is constrained by local environmental conditions (i.e., no access to savings accounts or fodder for purchase). Smallholder systems globally are undergoing diverse structural transformations, leading to increased livelihood diversification both within agriculture and into non-agricultural activities, increased intensification, and commodification and consolidation of land ownership (Barrett et al. 2010, De Schutter 2011, Alobo Loison 2015). Inclusion of such processes would affect our results. For example, including inorganic fertilizer as another mechanism to increase productivity would likely diminish the relative benefits of cover cropping, though fertilizer does not directly build SOM. Moderate fertilizer application and cover cropping could therefore be complementary practices (Giller et al. 1997). Non-farm employment opportunities may help to increase smallholder resilience under baseline conditions by providing a means through which the poor can step out of poverty (Hansen et al. 2019). Additionally, households may be willing to buy fodder to smooth their asset stocks even at the expense of their own consumption (Morduch 1995), which would reduce the effects of drought on asset stocks seen in our results. Future research could expand the scope of this stylistic model to include additional livelihood activities, behaviors, or exogenous drivers and better match it to specific empirical contexts.

Our study focused on potential benefits if support systems existed such that smallholders were able to adopt legume cover cropping and microinsurance. We did not incorporate household decision making with respect to uptake of the strategies or their spillover effects on other management practices. In reality, there exist financial, social, and informational barriers to the adoption of both ecological and financial strategies that have led to limited uptake in smallholder systems to date. Integrating decision making and approaches from ecological economics with the resilience perspective in this article is a promising avenue for future research.

\section{CONCLUSIONS AND RECOMMENDATIONS}

We assessed the effects of microinsurance and legume cover cropping on climate resilience in a stylized mixed crop-livestock smallholder system. Our study offers a fresh, reconciliatory perspective to the current debate on strategies for climate risk management and poverty reduction (Hansen et al. 2019). Distinct agricultural development communities and organizations advocate for microinsurance and ecologically based management, sometimes with strong ideological disagreements. By providing a rigorous comparative assessment of these strategies, we hope to bring these paradigms together, illuminate their complementarity, and seed future collaborative empirical assessments and integrated applications to programs and policies for sustainable development.

Our model results can be boiled down to this: insurance provides an important buffering effect to climate shocks, whereas legume cover cropping progressively decreases poverty and the impacts of shocks over time. Together, these benefits underscore the potential complementarity of economic and ecological adaptation strategies for smallholder resilience. Future development programs and empirical research could test this complementarity in different socio-environmental contexts, including how it develops over time and throughout a heterogeneous population of households. Finally, development resilience provides a useful conceptual framework for quantitative resilience analyses that jointly consider the capacities for poverty reduction and shock absorption (Dou et al. 2020). An integrated approach to resilience assessment shows promise to mitigate tradeoffs and harness complementarities so as to improve smallholder livelihoods and social-ecological functioning.

Responses to this article can be read online at: https://www.ecologyandsociety.org/issues/responses. php/12207

\section{Acknowledgments:}

The authors sincerely thank the three anonymous reviewers, whose suggestions greatly improved the quality of the paper. TGW was supported by funding from the German Federal Ministry of Education and Research (BMBF-01LN1315A) within the Junior Research Group POLISES, as well as a U.S. National Science Foundation (NSF) CNH Grant (Land transactions and investments: Impacts on agricultural production, ecosystem services, and food-energy security; DEB-1617364). GD acknowledges financial support by the BMBF within the project NamTip - Understanding and Managing Desertification Tipping Points in Dryland Social-Ecological Systems (FKZ: 01LC1821D). AES was supported by the NSF Graduate Research Fellowship Program and Rackham Graduate School at the University of Michigan. BM was supported by the Deutsche Forschungsgemeinschaft (DFG, German Research Foundation) in the project SEEMI (Social-Ecological Effects of Microinsurance; 321077328).

\section{Data Availability:}

The model is implemented in Python. All code supporting the findings of this study is openly available to download from CoMSES.net at https://www.comses.net/codebases/ ee47544a-7eb0-4482-8967-42d6b0c05060/releases/1.0.0/

\section{LITERATURE CITED}

Alobo Loison, S. 2015. Rural livelihood diversification in subSaharan Africa: a literature review. Journal of Development Studies 51(9):1125-1138. https://doi.org/10.1080/00220388.2015.1046445

Assefa, D., A. Nurfeta, and S. Banerjee. 2013. Assessment of feed resource availability and livestock production constraints in selected Kebeles of Adami Tullu Jiddo Kombolcha District, 
Ethiopia. African Journal of Agricultural Research 8 (29):4067-4073. [online] URL: https://academicjournals.org/ article/article1380882684 Assefa\%20et\%20al.pdf

Badgley, C., J. Moghtader, E. Quintero, E. Zakem, M. Jahi Chappell, K. Avilés-Vázquez, A. Samulon, and I. Perfecto. 2007. Organic agriculture and the global food supply. Renewable Agriculture and Food Systems 22(2):86-108. https://doi. org/10.1017/S1742170507001640

Barrett, C. B. 2005. Rural poverty dynamics: development policy implications. Agricultural Economics 32(s1):45-60. https://doi. org/10.1111/j.0169-5150.2004.00013.X

Barrett, C. B., B. J. Barnett, M. R. Carter, S. Chantarat, J. W. Hansen, A. G. Mude, D. Osgood, J. R. Skees, C. G. Turvey, and M. N. Ward. 2007. Poverty traps and climate risk: limitations and opportunities of index-based risk financing. IRI Technical Report No. 07-02. IRI, Chicago, Illinois, USA. https://doi.org/10.2139/ $\underline{\text { Ssrn. } 1141933}$

Barrett, C. B., and L. E. M. Bevis. 2015. The self-reinforcing feedback between low soil fertility and chronic poverty. Nature Geoscience 8:907-912. https://doi.org/10.1038/ngeo2591

Barrett, C. B., M. R. Carter, and C. P. Timmer. 2010. A centurylong perspective on agricultural development. American Journal of Agricultural Economics 92(2):447-468. https://doi.org/10.1093/ ajae/aaq005

Barrett, C. B., and M. A. Constas. 2014. Toward a theory of resilience for international development applications. Proceedings of the National Academy of Sciences 111(40):14625-14630. https:// doi.org/10.1073/pnas.1320880111

Baumgärtner, S., and M. F. Quaas. 2010. Managing increasing environmental risks through agrobiodiversity and agrienvironmental policies. Agricultural Economics 41(5):483-496. https://doi. org/10.1111/j.1574-0862.2010.00460.X

Bayala, J., G. W. Sileshi, R. Coe, A. Kalinganire, Z. Tchoundjeu, F. Sinclair, and D. Garrity. 2012. Cereal yield response to conservation agriculture practices in drylands of West Africa: a quantitative synthesis. Journal of Arid Environments 78:13-25. https://doi.org/10.1016/j.jaridenv.2011.10.011

Beck, M. W., O. Quast, and K. Pfliegner. 2019. Ecosystem-based adaptation and insurance: success, challenges and opportunities. InsuResilience Global Partnership, GIZ, Bonn, Germany. [online] URL: https://www.adaptationcommunity.net/wp-content/ uploads/2019/11/EbA insurance publication 2019 web.pdf

Bellemare, M. F., and C. B. Barrett. 2006. An ordered tobit model of market participation: evidence from Kenya and Ethiopia. American Journal of Agricultural Economics 88(2):324-337. https://doi.org/10.1111/j.1467-8276.2006.00861.x

Berre, D., T. Diarisso, N. Andrieu, C. Le Page, and M. Corbeels. 2021. Biomass flows in an agro-pastoral village in West-Africa: who benefits from crop residue mulching? Agricultural Systems 187(February):102981. https://doi.org/10.1016/j.agsy.2020.102981

Blanco-Canqui, H., M. M. Claassen, and D. R. Presley. 2012. Summer cover crops fix nitrogen, increase crop yield, and improve soil-crop relationships. Agronomy Journal 104:137-147. https:// doi.org/10.2134/agronj2011.0240
Bommarco, R., D. Kleijn, and S. G. Potts. 2013. Ecological intensification: harnessing ecosystem services for food security. Trends in Ecology and Evolution 28(4):230-238. https://doi. org/10.1016/j.tree.2012.10.012

Cabell, J. F., and M. Oelofse. 2012. An indicator framework for assessing agroecosystem resilience. Ecology and Society 17(1):18. https://doi.org/10.5751/ES-04666-170118

Carter, M. R., S. A. Janzen, and Q. Stoeffler. 2018. Can insurance help manage climate risk and food insecurity? Evidence from the pastoral regions of East Africa. Pages 201-225 in L. Lipper, N. McCarthy, D. Zilberman, S. Asfaw, and G. Branca, editors. Climate smart agriculture. Springer, Cham, Switzerland. https:// doi.org/10.1007/978-3-319-61194-5_10

Chantarat, S., A. G. Mude, C. B. Barrett, and C. G. Turvey. 2017. Welfare impacts of index insurance in the presence of a poverty trap. World Development 94:119-138. https://doi.org/10.1016/j. worlddev.2016.12.044

Cole, S., X. Giné, and J. Vickery. 2017. How does risk management influence production decisions? Evidence from a field experiment. Review of Financial Studies 30(6):1935-1970. https://doi. org/10.1093/rfs/hhw080

Dainese, M., E. A. Martin, M. A. Aizen, M. Albrecht, I. Bartomeus, R. Bommarco, L. G. Carvalheiro, R. ChaplinKramer, V. Gagic, L. A. Garibaldi, J. Ghazoul, H. Grab, M. Jonsson, D. S. Karp, C. M. Kennedy, D. Kleijn, C. Kremen, D. A. Landis, D. K. Letourneau, L. Marini, K. Poveda, R. Rader, H. G. Smith, T. Tscharntke, G. K. S. Andersson, I. Badenhausser, S. Baensch, A. D. M. Bezerra, F. J. J. A. Bianchi, V. Boreux, V. Bretagnolle, B. Caballero-Lopez, P. Cavigliasso, A. Ćetković, N. P. Chacoff, A. Classen, S. Cusser, F. D. da Silva e Silva, G. A. de Groot, J. H. Dudenhöffer, J. Ekroos, T. Fijen, P. Franck, B. M. Freitas, M. P. D. Garratt, C. Gratton, J. Hipólito, A. Holzschuh, L. Hunt, A. L. Iverson, S. Jha, T. Keasar, T. N. Kim, M. Kishinevsky, B. K. Klatt, A.-M. Klein, K. M. Krewenka, S. Krishnan, A. E. Larsen, C. Lavigne, H. Liere, B. Maas, R. E. Mallinger, E. Martinez Pachon, A. Martínez-Salinas, T. D. Meehan, M. G. E. Mitchell, G. A. R. Molina, M. Nesper, L. Nilsson, M. E. O’Rourke, M. K. Peters, M. Plećaš, S. G. Potts, D. de L. Ramos, J. A. Rosenheim, M. Rundlöf, A. Rusch, A. Sáez, J. Scheper, M. Schleuning, J. M. Schmack, A. R. Sciligo, C. Seymour, D. A. Stanley, R. Stewart, J. C. Stout, L. Sutter, M. B. Takada, H. Taki, G. Tamburini, M. Tschumi, B. F. Viana, C. Westphal, B. K. Willcox, S. D. Wratten, A. Yoshioka, C. Zaragoza-Trello, W. Zhang, Y. Zou, and I. Steffan-Dewenter. 2019. A global synthesis reveals biodiversity-mediated benefits for crop production. Science Advances 5(10):eaax0121. https:// doi.org/10.1126/sciadv.aax0121

De Schutter, O. 2011. The green rush: the global race for farmland and the rights of land users. Harvard International Law Journal 52:503-556. [online] URL: https://harvardilj.org/wp-content/ uploads/sites/15/2011/07/HILJ_52-2_De-Schutter1.pdf

Dell'Angelo, J., P. D’Odorico, and M. C. Rulli. 2017. Threats to sustainable development posed by land and water grabbing. Current Opinion in Environmental Sustainability 26-27:120-128. https://doi.org/10.1016/j.cosust.2017.07.007 
DeLonge, M. S., A. Miles, and L. Carlisle. 2016. Investing in the transition to sustainable agriculture. Environmental Science and Policy 55:266-273. https://doi.org/10.1016/j.envsci.2015.09.013

Dorward, A. 2009. Integrating contested aspirations, processes and policy: development as hanging in, stepping up and stepping out. Development Policy Review 27(2):131-146. https://doi. org/10.1111/j.1467-7679.2009.00439.x

Dressler, G., J. Groeneveld, C. M. Buchmann, C. Guo, N. Hase, J. Thober, K. Frank, and B. Müller. 2019. Implications of behavioral change for the resilience of pastoral systems - lessons from an agent-based model. Ecological Complexity 40:100710. https://doi.org/10.1016/j.ecocom.2018.06.002

Drinkwater, L. E., P. Wagoner, and M. Sarrantonio. 1998. Legume-based cropping systems have reduced carbon and nitrogen losses. Nature 396(6708):262-265. https://doi.org/10.1038/24376

Duff, A. J., P. H. Zedler, J. A. Barzen, and D. L. Knuteson. 2017. The capacity-building stewardship model: assessment of an agricultural network as a mechanism for improving regional agroecosystem sustainability. Ecology and Society 22(1):45. https://doi.org/10.5751/ES-09146-220145

Dou, Y., P. J. Deadman, M. Berbés-Blázquez, N. D. Vogt, and O. Almeida. 2020. Pathways out of poverty through the lens of development resilience: an agent-based simulation. Ecology and Society 25(4):3. https://doi.org/10.5751/ES-11842-250403

Egli, L., H. Weise, V. Radchuk, R. Seppelt, and V. Grimm. 2019. Exploring resilience with agent-based models: state of the art, knowledge gaps and recommendations for coping with multidimensionality. Ecological Complexity 40(B):100718. https://doi.org/10.1016/j.ecocom.2018.06.008

Ewansiha, S. U., and B. B. Singh. 2006. Relative drought tolerance of important herbaceous legumes and cereals in the moist and semi-arid regions of West Africa. Journal of Food, Agriculture and Environment 4:188-190.

Food and Agriculture Organization of the United Nations (FAO). 2018. Agroecology: a pathway to achieving the SDGs. Rural 21. [online] URL: https://www.rural21.com/english/news/detail/ article/agroecology-a-pathway-to-achieving-the-sdgs.html?no cache $=1$

Finger, R., and N. Buchmann. 2015. An ecological economic assessment of risk-reducing effects of species diversity in managed grasslands. Ecological Economics 110:89-97. https://doi. org/10.1016/j.ecolecon.2014.12.019

Fisher, E., J. Hellin, H. Greatrex, and N. Jensen. 2019. Index insurance and climate risk management: addressing social equity. Development Policy Review 37:681-602. https://doi.org/10.1111/ dpr.12387

Florentín, M. A., M. Peñalva, A. Calegari, and R. Derpsch. 2011. Green manurelcover crops and crop rotation in conservation agriculture on small farms. Plant Production and Protection Division, Food and Agriculture Organization of the United Nations, Rome, Italy.

Folke, C. 2016. Resilience (Republished). Ecology and Society 21 (4):44. https://doi.org/10.5751/ES-09088-210444
Giller, K. E., G. Cadisch, C. Ehaliotis, E. Adams, W. D. Sakala, and P. L. Mafongoya. 1997. Building soil nitrogen capital in Africa. Pages 151-192 in R. J. Buresh, P. A. Sanchez, and F. Calhoun, editors. Replenishing soil fertility in Africa. Soil Science Society of America and American Society of Agronomy, Madison, Wisconsin, USA. https://doi.org/10.2136/sssaspecpub51. $\underline{\mathrm{c} 7}$

Grimm, V., E. Revilla, U. Berger, F. Jeltsch, W. M. Mooij, S. F. Railsback, H.-H. Thulke, J. Weiner, T. Wiegand, and D. L. DeAngelis. 2005. Pattern-oriented modeling of agent-based complex systems: lessons from ecology. Science 310 (5750):987-991. https://doi.org/10.1126/science.1116681

Haider, L. J., W. J. Boonstra, G. D. Peterson, and M. Schlüter. 2018. Traps and sustainable development in rural areas: a review. World Development 101:311-321. https://doi.org/10.1016/j. worlddev.2017.05.038

Hansen, J., J. Hellin, T. Rosenstock, E. Fisher, J. Cairns, C. Stirling, C. Lamanna, J. van Etten, A. Rose, and B. Campbell. 2019. Climate risk management and rural poverty reduction. Agricultural Systems 172:28-46. https://doi.org/10.1016/j. agsy.2018.01.019

Hazell, P., J. Anderson, N. Balzer, A. Hastrup Clemmensen, U. Hess, and F. Rispoli. 2010. The potential for scale and sustainability in weather index insurance for agriculture and rural livelihoods. International Fund for Agricultural Development and World Food Programme, Rome, Italy. [online] URL: https:// www.ifad.org/documents/38714170/40239486/The+potential+for+ scale+and+sustainability + in +weather+index + insurance + for+agriculture + and+rural+livelihoods.pdf/7a8247c7-d7be-4a1b-9088-37edee6717ca

High Level Panel of Experts on Food Security and Nutrition (HLPE). 2019. Agroecological and other innovative approaches for sustainable agriculture and food systems that enhance food security and nutrition. High Level Panel of Experts on Food Security and Nutrition of the Committee on World Food Security, Rome, Italy. http://www.fao.org/3/ca5602en/ca5602en.pdf

Holling, C. S. 1973. Resilience and stability of ecological systems. Annual Review of Ecology and Systematics 4(1):1-23. https://doi. org/10.1146/annurev.es.04.110173.000245

Iooss, B., and P. Lemaître. 2015. A review on global sensitivity analysis methods. Pages 101-122 in G. Dellino and C. Meloni, editors. Uncertainty management in simulation-optimization of complex systems: algorithms and applications. Springer, Boston, Massachusetts, USA. https://doi.org/10.1007/978-1-4899-7547-8 5

Jacobi, J., S. Mukhovi, A. Llanque, H. Augstburger, F. Käser, C. Pozo, M. Ngutu Peter, J. M. F. Delgado, B. P. Kiteme, S. Rist, and C. Ifejika Speranza. 2018. Operationalizing food system resilience: an indicator-based assessment in agroindustrial, smallholder farming, and agroecological contexts in Bolivia and Kenya. Land Use Policy 79:433-446. https://doi.org/10.1016/j. landusepol.2018.08.044

John, F., R. Toth, K. Frank, J. Groeneveld, and B. Müller. 2019. Ecological vulnerability through insurance? Potential unintended consequences of livestock drought insurance. Ecological Economics 157:357-368. https://doi.org/10.1016/j.ecolecon.2018.11.021 
Karlan, D., R. D. Osei, I. Osei-Akoto, and C. Udry. 2014. Agricultural decisions after relaxing credit and risk constraints. Quarterly Journal of Economics 129(2):597-652. https:// econpapers.repec.org/article/oupqjecon/v_3a129 3ay 3a2014_3ai 3a2 3ap 3a597-652.htm

Kaye, J. P., and M. Quemada. 2017. Using cover crops to mitigate and adapt to climate change. A review. Agronomy for Sustainable Development 37(1):4. https://doi.org/10.1007/s13593-016-0410-X

Kaye-Blake, W., C. Schilling, R. Monaghan, R. Vibart, S. Dennis, and E. Post. 2019. Quantification of environmental-economic trade-offs in nutrient management policies. Agricultural Systems 173:458-468. https://doi.org/10.1016/j.agsy.2019.03.013

Kramer, B., and F. Ceballos. 2018. Enhancing adaptive capacity through climate-smart insurance: theory and evidence from India. Presented at the 2018 International Conference of Agricultural Economists, Vancouver, British Columbia, July 28-August 2, 2018. http://ageconsearch.umn.edu/record/275926>

Kramer, B., J. Hellin, J. Hansen, A. Rose, and M. Braun. 2019. Building resilience through climate risk insurance: insights from agricultural research for development. Working Paper, CGIAR, Wageningen, the Netherlands. [online] URL: https://hdl.handle. net/10568/106171

Kremmydas, D., I. N. Athanasiadis, and S. Rozakis. 2018. A review of Agent Based Modeling for agricultural policy evaluation. Agricultural Systems 164:95-106. https://doi. org/10.1016/j.agsy.2018.03.010

Lamine, C., and S. Bellon. 2009. Conversion to organic farming: a multidimensional research object at the crossroads of agricultural and social sciences. A review. Agronomy for Sustainable Development 29(1):97-112. https://doi.org/10.1051/ agro:2008007

Lempert, R. J. 2002. A new decision sciences for complex systems. Proceedings of the National Academy of Sciences 99 Suppl3 (May):7309-7313. https://doi.org/10.1073/pnas.082081699

Lin, B. B. 2011. Resilience in agriculture through crop diversification: adaptive management for environmental change. Bioscience 61(3):183-193. https://doi.org/10.1525/bio.2011.61.3.4

Lybbert, T. J., and M. R. Carter. 2015. Bundling drought tolerance and index insurance to reduce rural household vulnerability to drought. Pages 401-414 in A. M. Balisacan, U. Chakravorty, and M.-L. V. Ravago, editors. Sustainable economic development. Academic, San Diego, California, USA. https://doi.org/10.1016/ B978-0-12-800347-3.00022-4

Magliocca, N. R., D. G. Brown, and E. C. Ellis. 2013. Exploring agricultural livelihood transitions with an agent-based virtual laboratory: global forces to local decision-making. PLoS One 8 (9):e73241. https://doi.org/10.1371/journal.pone.0073241

Martini, E. A., J. S. Buyer, D. C. Bryant, T. K. Hartz, and R. F. Denison. 2004. Yield increases during the organic transition: improving soil quality or increasing experience? Field Crops Research 86(2):255-266. https://doi.org/10.1016/j.fcr.2003.09.002

Mobarak, A. M., and M. R. Rosenzweig. 2013. Informal risk sharing, index Insurance, and risk taking in developing countries.
American Economic Review 103(3):375-380. https://doi. org/10.1257/aer.103.3.375

Morduch, J. 1995. Income smoothing and consumption smoothing. Journal of Economic Perspectives 9(3):103-114. https://doi.org/10.1257/jep.9.3.103

Moyo, S., and F. J. C. Swanepoel. 2010. Multifunctionality of livestock in developing communities. Pages 1-13 in F. Swanepoel, A. Stroebel, and S. Moyo, editors. Role of livestock in developing communities: enhancing multifunctionality. Technical Centre for Agricultural and Rural Cooperation, Wageningen, The Netherlands; University of the Free State, Bloemfontein, South Africa; International Livestock Research Institute, Nairobi, Kenya.

Müller, B., F. Bohn, G. Dreßler, J. Groeneveld, C. Klassert, R. Martin, M. Schlüter, J. Schulze, H. Weise, and N. Schwarz. 2013. Describing human decisions in agent-based models - ODD + D, an extension of the ODD protocol. Environmental Modelling and Software 48:37-48. https://doi.org/10.1016/j.envsoft.2013.06.003

Müller, B., L. Johnson, and D. Kreuer. 2017. Maladaptive outcomes of climate insurance in agriculture. Global Environmental Change 46:23-33. https://doi.org/10.1016/j. gloenvcha.2017.06.010

Müller, B., and D. Kreuer. 2016. Ecologists should care about insurance, too. Trends in Ecology and Evolution 31(1):1-2. https:// doi.org/10.1016/j.tree.2015.10.006

Müller, B., M. F. Quaas, K. Frank, and S. Baumgärtner. 2011. Pitfalls and potential of institutional change: rain-index insurance and the sustainability of rangeland management. Ecological Economics 70(11):2137-2144. https://doi.org/10.1016/ j.ecolecon.2011.06.011

O'Connor, C. 2013. Soil matters: how the federal crop insurance program should be reformed to encourage low-risk farming methods with high-reward environmental outcomes. Natural Resources Defense Council, New York, New York, USA. [online] URL: https://www.nrdc.org/sites/default/files/soil-matters-IP.pdf

O'Hare, P., I. White, and A. Connelly. 2016. Insurance as maladaptation: resilience and the 'business as usual' paradox. Environment and Planning. C, Government and Policy 34 (6):1175-1193. https://doi.org/10.1177/0263774x 15602022

Powell, J. M., R. A. Pearson, and P. H. Hiernaux. 2004. Croplivestock onteractions in the West African drylands. Agronomy Journal 96:469-483. https://doi.org/10.2134/agronj2004.4690

Quaas, M., S. Baumgärtner, and M. De Lara. 2019. Insurance value of natural capital. Ecological Economics 165:106388. https://doi.org/10.1016/j.ecolecon.2019.106388

Reeves, D. W. 1997. The role of soil organic matter in maintaining soil quality in continuous cropping systems. Soil and Tillage Research 43(1):131-167. https://doi.org/10.1016/S0167-1987(97) 00038-X

Robertson, G. P., and P. M. Vitousek. 2009. Nitrogen in agriculture: balancing the cost of an essential resource. Annual Review of Environment and Resources 34(1):97-125. https://doi. org/10.1146/annurev.environ.032108.105046 
Rosa-Schleich, J., J. Loos, O. Mußhoff, and T. Tscharntke. 2019. Ecological-economic trade-offs of diversified farming systems a review. Ecological Economics 160:251-263. https://doi. org/10.1016/j.ecolecon.2019.03.002

Schaub, S., N. Buchmann, A. Lüscher, and R. Finger. 2020. Economic benefits from plant species diversity in intensively managed grasslands. Ecological Economics 168:106488. https:// doi.org/10.1016/j.ecolecon.2019.106488

Schreinemachers, P., T. Berger, and J. B. Aune. 2007. Simulating soil fertility and poverty dynamics in Uganda: a bio-economic multi-agent systems approach. Ecological Economics 64 (2):387-401. https://doi.org/10.1016/j.ecolecon.2007.07.018

Serraj, R., T. R. Sinclair, and L. C. Purcell. 1999. Symbiotic N2 fixation response to drought. Journal of Experimental Botany 50 (331):143-155. https://doi.org/10.1093/jxb/50.331.143

Shankarnarayan, K. A., L. N. Harsh, and S. Kathju. 1987. Agroforestry in the arid zones of India. Agroforestry Systems 5 (1):69-88. https://doi.org/10.1007/BF00046414

Shennan, C. 2008. Biotic interactions, ecological knowledge and agriculture. Philosophical Transactions of the Royal Society B: Biological Sciences 363(1492):717-739. https://doi.org/10.1098/ $\underline{\text { rstb. } 2007.2180}$

Snapp, S. S., S. M. Swinton, R. Labarta, D. Mutch, J. R. Black, R. Leep, J. Nyiraneza, and K. O’Neil. 2005. Evaluating cover crops for benefits, costs and performance within cropping system niches. Agronomy Journal 97:322-332.

Stephens, E. C., C. F. Nicholson, D. R. Brown, D. Parsons, C. B. Barrett, J. Lehmann, D. Mbugua, S. Ngoze, A. N. Pell, and S. J. Riha. 2012. Modeling the impact of natural resource-based poverty traps on food security in Kenya: the crops, livestock and soils in smallholder economic systems (CLASSES) model. Food Security 4(3):423-439. https://doi.org/10.2139/ssrn.1844623

Stratton, A. E., L. Kuhl, and J. Blesh. 2020. Ecological and nutritional functions of agroecosystems as indicators of smallholder resilience. Frontiers in Sustainable Food Systems 4:173. https://doi.org/10.3389/fsufs.2020.543914

Stratton, A. E., H. Wittman, and J. Blesh. 2021. Diversification supports farm income and improved working conditions during agroecological transitions in southern Brazil. Agronomy for Sustainable Development 41:35(2021). https://doi.org/10.1007/ s13593-021-00688-X

Sun, Z., I. Lorscheid, J. D. Millington, S. Lauf, N. R. Magliocca, J. Groeneveld, S. Balbi, H. Nolzen, B. Müller, J. Schulze, and C. M. Buchmann. 2016. Simple or complicated agent-based models? A complicated issue. Environmental Modelling and Software 86:56-67. https://doi.org/10.1016/j.envsoft.2016.09.006

SwissRe. 2013. Partnering for food security in emerging markets. Swiss Reinsurance Company, Zurich, Switzerland. [online] URL: https://www.swissre.com/dam/jcr:dbafcfed-d5c7-406b-a2e1-d2ea4ad020e0/ sigma1 2013 en.pdf

Thornton, P. K., and M. Herrero. 2015. Adapting to climate change in the mixed crop and livestock farming systems in subSaharan Africa. Nature Climate Change 5(9):830-836. https://doi. org/10.1038/nclimate2754
Tittonell, P. 2014. Livelihood strategies, resilience and transformability in African agroecosystems. Agricultural Systems 126:3-14. https://doi.org/10.1016/j.agsy.2013.10.010

Tittonell, P., and K. E. Giller. 2013. When yield gaps are poverty traps: the paradigm of ecological intensification in African smallholder agriculture. Field Crops Research 143:76-90. https:// doi.org/10.1016/i.fcr.2012.10.007

Tomich, T. P., P. Lidder, M. Coley, D. Gollin, R. Meinzen-Dick, P. Webb, and P. Carberry. 2019a. Food and agricultural innovation pathways for prosperity. Agricultural Systems 172:1-15. https:// doi.org/10.1016/j.agsy.2018.01.002

Tomich, T. P., P. Lidder, J. Dijkman, M. Coley, P. Webb, and M. Gill. 2019b. Agri-food systems in international research for development: ten theses regarding impact pathways, partnerships, program design, and priority-setting for rural prosperity. Agricultural Systems 172:101-109. https://doi.org/10.1016/j. agsy.2018.12.004

Unger, P. W., and M. F. Vigil. 1998. Cover crop effects on soil water relationships. Journal of Soil and Water Conservation 53 (3):200-207.

Valbuena, D., O. Erenstein, S. Homann-Kee Tui, T. Abdoulaye, L. Claessens, A. J. Duncan, B. Gérard, M. C. Rufino, N. Teufel, A. van Rooyen, and M. T. van Wijk. 2012. Conservation agriculture in mixed crop-livestock systems: scoping crop residue trade-offs in Sub-Saharan Africa and South Asia. Field Crops Research 132:175-184. https://doi.org/10.1016/j.fcr.2012.02.022

Valente, D., P. P. Miglietta, D. Porrini, M. R. Pasimeni, G. Zurlini, and I. Petrosillo. 2019. A first analysis on the need to integrate ecological aspects into financial insurance. Ecological Modelling 392:117-127. https://doi.org/10.1016/j.ecolmodel.2018.11.009

Walker, B. H. 2020. Resilience: what it is and is not. Ecology and Society 25(2):11. https://doi.org/10.5751/ES-11647-250211

Weise, H., H. Auge, C. Baessler, I. Bärlund, E. M. Bennett, U. Berger, F. Bohn, A. Bonn, D. Borchardt, F. Brand, A. Chatzinotas, R. Corstanje, F. De Laender, P. Dietrich, S. Dunker, W. Durka, I. Fazey, J. Groeneveld, C. S. E. Guilbaud, H. Harms, S. Harpole, J. Harris, K. Jax, F. Jeltsch, K. Johst, J. Joshi, S. Klotz, I. Kühn, C. Kuhlicke, B. Müller, V. Radchuk, H. Reuter, K. Rinke, M. Schmitt-Jansen, R. Seppelt, A. Singer, R. J. Standish, H. Thulke, B. Tietjen, M. Weitere, C. Wirth, C. Wolf, and V. Grimm. 2020. Resilience trinity: safeguarding ecosystem functioning and services across three different time horizons and decision contexts. Oikos 129:445-456. https://doi.org/10.1111/oik.07213

Williams, T. G., S. D. Guikema, D. G. Brown, and A. Agrawal. 2020. Resilience and equity: quantifying the distributional effects of resilience-enhancing strategies in a smallholder agricultural system. Agricultural Systems 182:102832. https://doi.org/10.1016/ j.agsy.2020.102832

Wittwer, R. A., B. Dorn, W. Jossi, and M. G. A. van der Heijden. 2017. Cover crops support ecological intensification of arable cropping systems. Scientific Reports 7:41911. https://doi. org/10.1038/srep41911

Wong, H. L., X. Wei, H. B. Kahsay, Z. Gebreegziabher, C. Gardebroek, D. E. Osgood, and R. Diro. 2020. Effects of input 
Ecology and Society 26(2): 14 https://www.ecologyandsociety.org/vol26/iss2/art14/

vouchers and rainfall insurance on agricultural production and household welfare: experimental evidence from northern Ethiopia. World Development 135:105074. https://doi.org/10.1016/ j.worlddev.2020.105074 


\section{APPENDIX 1 ODD+D model description}

\section{A1.1 Overview}

\section{A1.1.1 Purpose}

The model was developed to investigate the short- and long-term resilience of a smallholder agricultural farming system and the effects of different household-level adaptation strategies on this resilience. It is intended to be used by researchers interested in exploring long-term dynamics of agricultural adaptation options. The model represents a mixed crop-livestock agricultural system, designed to be generally representative of a smallholder agricultural system in the Global South. Given the interest in exploring the general mechanisms through which different adaptation options affect resilience, the model is intentionally stylized and does not draw from empirical data to be representative of a specific location.

\section{A1.1.2 Entities, state variables, and scales}

The model represents smallholder households that engage in agriculture and carry their wealth in the form of livestock. Each household is defined by a static land holding and has dynamic income and livestock holdings. Livestock are grazed on a combination of on-farm crop residues and an external rangeland, which is not explicitly modeled. The household's land has an evolving level of organic nutrients, which represent SOM and soil organic $\mathrm{N}$ together in a stylized manner. The model is spatially implicit, no environmental feedbacks beyond the household scale are represented, and households do not interact with each other.

\section{A1.1.3 Process overview and scheduling}

The model operates at an annual time scale. Each year of the simulation involves calculation of: (1) soil nutrient flows; (2) crop yields; (3) household income; and (4) household wealth and coping measures (Figure A1.1). 


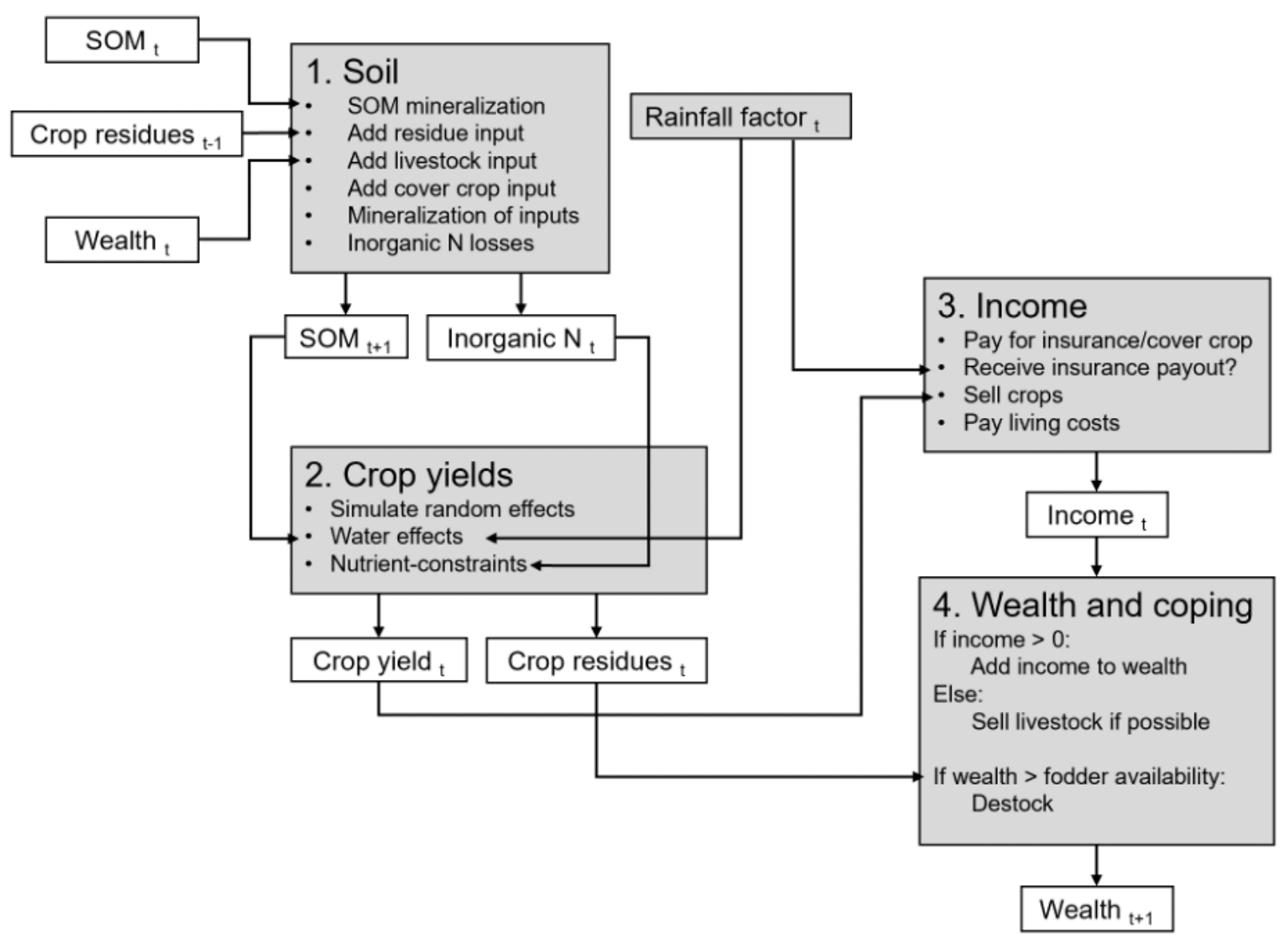

Figure A1.1: Overview of annual simulation process.

\section{A1.2 Design concepts}

\section{A1.2.1 Theoretical and empirical background}

The model represents soil nutrient dynamics in a stylized way. It models slow-evolving stocks of SOM and faster-acting pools of mineralized nutrients. Our representation is consistent with soil representations in biogeochemical models (Manzoni and Porporato 2009) and is qualitatively comparable to other more complicated process-based models of soil nutrient dynamics used for agricultural applications (e.g., CENTURY (Metherell et al. 1993), DSSAT (Jones et al. 2003), and APSIM (Keating et al. 2003)).

Our crop yield model assumes that yields are influenced jointly by climate and nutrient availability. This representation generally follows Liebig's law of the minimum, which assumes that yields are influenced solely by the most constraining of these factors and plateau when each factor is above some threshold (Tittonell and Giller 2013, Ferreira et al. 2017) (i.e., the crop can be water- or nutrient-limited). Similar representations are used in other more complicated process-based models of crop yield (e.g., CENTURY (Metherell et al. 1993), STICS (Brisson et al. 2003)) and in other simulation models (Grillot et al. 2018). 
Together, our soil nutrient and crop yield representations exhibit the following qualitative characteristics:

1) Consistent cropping without replenishment of organic matter will slowly degrade soil quality and hence crop yields over time (Giller et al. 1997, Reeves 1997, Bennett et al. 2012);

2) Soil quality can be maintained and built through organic inputs (e.g., manure or leguminous cover crops) (Giller et al. 1997, Drinkwater et al. 1998, Wittwer et al. 2017); and

3) Soil organic matter has benefits for drought sensitivity and nutrient losses (Drinkwater et al. 1998, Bommarco et al. 2013).

Household decision-making represents wealth accumulation and coping measures, and is modeled using a simple heuristic. This heuristic assumes that: (1) households store their wealth in the form of livestock and do not have cash savings; (2) livestock are sold if necessary to meet immediate cash needs (Bellemare and Barrett 2006, Moyo and Swanepoel 2010); and (3) total herd size is limited by feed availability (Valbuena et al. 2012, Assefa et al. 2013).

\section{A1.2.2 Individual decision making}

The household makes two decisions related to their livestock wealth reserves, both of which are governed by simple heuristics. First, if the household's income in a given year is negative, they make up the deficit by drawing from their wealth reserves (a proxy for the selling of livestock). If wealth reserves are insufficient to make up the deficit, we assume that the household reduces their consumption. Both livestock selling and consumption reduction are considered as coping mechanisms. If, instead, their income is positive, they add this surplus to their wealth reserves (a proxy for the buying of livestock). This latter case is mediated by the second heuristic; if a household's livestock herd (i.e., wealth reserves) is larger than could be fed by their crop residues (assuming some percentage of their herd is grazed on common pastures), they are forced to destock these animals that cannot be fed. Given that wealth can only be held in the form of livestock - i.e., we do not model financial resources - the household receives no monetary benefit for this destocking.

These heuristics are not influenced by any other factors and there are no notions of beliefs, memory, learning, adaptation, or social or cultural norms.

\section{A1.2.3 Learning}

There is no notion of learning in the household's decision-making. 


\section{A1.2.4 Individual sensing}

Each year, the household observes its crop yields, residue production, and income, which influence the decision heuristics.

\section{A1.2.5 Individual prediction}

The household does not predict future conditions.

\section{A1.2.6 Interaction}

There are no interactions between households. Livestock are assumed to be partially grazed on common rangeland, which implies interactions with other households, but we do not explicitly model the rangeland dynamics, so this interaction is not endogenous to the model.

\section{A1.2.7 Collectives}

The household does not form collectives.

\section{A1.2.8 Heterogeneity}

The household is defined by its initial wealth reserves, initial soil quality, and land holdings. In our simulations, we consider only the implications of different levels of land holdings. Given that there are no interactions in our model, running the simulation for three households with heterogeneous land endowments is equivalent to running it three times separately with a single household.

\section{A1.2.9 Stochasticity}

There are two sources of stochasticity in the model: (1) the generation of yearly climate conditions, which is constant across all households; and (2) a household-level random effect in the calculation of crop yields. The household-level effect conceptually represents other nonmodeled factors that may influence crop yields, household-level (positive or negative) shocks, and household-level variability in the experience of the regional climate condition. Together, this requires us to simulate a set of hypothetical climate time series and, for each time series, run the model for a set of households that experience different random crop yield effects. Under the baseline model settings, the variability of the household-level effect is approximately half that of the region-level effect. The model therefore allows for considerable path dependencies introduced by household-level stochasticity.

\section{A1.2.10 Observation}

Model outputs include yields, income, wealth, soil organic matter, and mineralized nutrients. These are observed at the household level at an annual basis. 


\section{A1.2.11 Emergence}

There exists a positive feedback loop, in which positive income enables accumulation of livestock (wealth reserves), providing additional soil organic matter, which in turn increases future crop yields and income. The ability for the household to experience this positive feedback cycle is mediated by their land endowment, initial soil organic matter, climate, and random yield effects. As such, household "trajectories" emerge as a combination of these random and nonrandom factors. Given the importance of stochasticity, there exists a considerable degree of path dependence in the model; a household that is unlucky one year (i.e., has a large, negative random effect in their crop yields) may be pushed into a downward spiral of decreasing livestock herds, soil organic matter, crop yields, and income. We investigate the possibility for household adaptation options (cover cropping and insurance) to influence these trajectories and hence contribute to different emergent outcomes.

\section{A1.3 Details}

\section{A1.3.1 Implementation details}

The model is implemented in Python 3.6. Code is available online at CoMSES.net: https://www.comses.net/codebases/ee47544a-7eb0-4482-8967-42d6b0c05060/releases/1.0.0/

\section{A1.3.2 Initialization}

The model is stylized and does not draw from any extensive empirical datasets. To initialize a single simulation, the climate time series is first generated, followed by a population of households with heterogeneous land endowments. Household initial wealth and soil organic matter levels are homogeneous and are specified by exogenous parameters (see section A1.3.3). As stated above, a single model with multiple households is functionally no different to multiple models with a single household, but we do it in this way both for computational efficiency (through vectorization of calculations) and simpler management of random number seeds. Within an experiment, the random number seed is the only factor that is varied upon initialization.

\section{A1.3.3 Input data and parameterization}

Model parameterization is achieved through a combination of information from literature and a pattern-oriented modeling calibration process. All model parameters are displayed in Table A1.1. The calibration process is described in section A1.3.5. Although we do not intend the model to be representative of any specific region or location, we chose to draw several of the parameters from Ethiopian data sources. Ethiopia's population is primarily engaged in smallholder agriculture - many in mixed crop-livestock systems - and thus Ethiopia serves as a relevant setting from which to draw stylized information. This enabled us to represent the relative scales of different model elements (e.g., maximum crop yields and crop selling prices) without requiring these values to be determined by the calibration process, thus reducing the dimensionality of the uncertain parameter set. 
Additionally, although our representation of soil nutrient dynamics is stylized and we do not claim to realistically represent actual nutrient flows, we measure the SOM pool in units of kilograms of nitrogen per hectare ( $\mathrm{kg} \mathrm{N} / \mathrm{ha}$ ). This again allowed us to ground several parameters in empirically observed values (e.g., nitrogen-fixation of cover crops), reducing the number of uncertain parameters. However, we note that some values, particularly the C: $\mathrm{N}$ ratios, remain unrealistic in this model parameterization.

The derivation of several parameters requires some explanation:

- Initial and maximum SOM: In reality, baseline amounts of organic matter in a nondegraded soil are sufficient to provide nutrients for moderate levels of crop yield. To parameterize the initial SOM, we used information from other parameters to give a rough estimate of a reasonable value. Specifically, we assumed that the soil itself would initially be able to provide $4,000 \mathrm{~kg} / \mathrm{ha}$ crop yield (approximately 2/3 of the maximum yield) in the absence of other inputs. Using the C:N ratio in the crop (50), this is equivalent to 80 $\mathrm{kg} \mathrm{N} / \mathrm{ha}$ of mineralized inorganic $\mathrm{N}$ that is produced solely through mineralization from SOM. With a mineralization rate of 0.02 , this requires an initial SOM level of 4,000 $\mathrm{kg} / \mathrm{ha}$. We then chose the maximum SOM level to be double the initial SOM level.

- Wealth to nitrogen conversion: Using values from Newcombe (1987), we calculated that a cattle might produce $6,165 \mathrm{~kg}$ of fresh dung or, equivalently, 5,364 $\mathrm{kg}$ of dry matter per year. Assuming that $1.46 \%$ of the dry weight is nitrogen (also comparable to Lupwayi et al. (2000)), this equates to $78.3 \mathrm{~kg} \mathrm{~N} /$ cattle/year. Assuming a price of 3,000 birr (the Ethiopian currency) for a single animal, this is equivalent to $0.026 \mathrm{~kg} \mathrm{~N} / \mathrm{year} / \mathrm{birr}$.

- Land endowment: In reality, smallholder land holdings vary by a larger degree than we represent in the model. However, we assume that each household - regardless of their land endowment and wealth - has the same annual living costs. In reality, land-rich households might have more household members, and consumption also generally increases with wealth. For simplicity in the analysis, our households vary over a single dimension (land endowment), so we do not incorporate such secondary effects and hence parameterize the variability in land endowment from only 1 to 2 ha. These values respectively correspond to the $47^{\text {th }}$ and $75^{\text {th }}$ quantiles of household landholdings in the Ethiopia 2015 LSMS data.

Table A1.1: Parameter values and sources.

\begin{tabular}{|c|c|c|c|c|c|c|c|}
\hline Parameter & Symbol & Value & Unit & Source & $\begin{array}{l}\text { Uncer- } \\
\text { tain }^{+}\end{array}$ & $\begin{array}{l}\text { Sensit- } \\
\text { ivity } \\
\text { analysis }\end{array}$ & Description / notes \\
\hline Simulation settings & & & & & & & \\
\hline $\begin{array}{l}\text { Number of } \\
\text { households }\end{array}$ & $N_{A}$ & 200 & - & & & & \\
\hline Random seed & $s$ & 0 & - & & & & Varied over simulation runs \\
\hline
\end{tabular}




\begin{tabular}{|c|c|c|c|c|c|c|c|}
\hline Parameter & Symbol & Value & Unit & Source & \multirow{2}{*}{$\begin{array}{l}\text { Uncer- } \\
\text { tain }^{+}\end{array}$} & $\begin{array}{l}\text { Sensit- } \\
\text { ivity } \\
\text { analysis }\end{array}$ & \multirow[t]{2}{*}{ Description / notes } \\
\hline \multirow{2}{*}{\multicolumn{8}{|c|}{ Households }} \\
\hline & & & & & & & \\
\hline \begin{tabular}{l|l} 
Land \\
endowment
\end{tabular} & $L$ & $\begin{array}{l}\{1,1.5, \\
2\}\end{array}$ & ha & & & $\checkmark$ & $\begin{array}{l}\text { Varied over households. See text in } \\
\text { section A1.3.3. }\end{array}$ \\
\hline Initial wealth & $W_{0}$ & 36,165 & birr & & $\checkmark$ & $\checkmark$ & Proxy for livestock. \\
\hline $\begin{array}{l}\text { Cash } \\
\text { requirement }\end{array}$ & $C R$ & 6,001 & birr & & $\checkmark$ & $\checkmark$ & $\begin{array}{l}\text { Annual cash requirement for } \\
\text { consumption. }\end{array}$ \\
\hline & & & & & & & \\
\hline \multicolumn{8}{|l|}{ Market } \\
\hline \begin{tabular}{l|l} 
Crop sell price
\end{tabular} & $P_{\text {crop }}$ & 2.17 & birr/kg & $\mathrm{FAO}^{\ddagger}$ & & & $\begin{array}{l}\text { Mean } 2015 \text { price for Maize in Addis } \\
\text { Ababa. }\end{array}$ \\
\hline Livestock price & $P_{l s}$ & 3,000 & birr/head & $\mathrm{CSA}^{\S}$ & & & Average 2015 price. \\
\hline & & & & & & & \\
\hline \multicolumn{8}{|l|}{ Yields } \\
\hline \begin{tabular}{l|l} 
Crop C:N \\
\end{tabular} & $C N_{\text {crop }}$ & 50 & $\mathrm{gC/gN}$ & $\begin{array}{l}\text { (Methere } \\
\text { ll et al. } \\
\text { 1993) }\end{array}$ & & $\checkmark$ & $\begin{array}{l}\text { Carbon to nitrogen ratio in harvested } \\
\text { crop. Value loosely taken from the } \\
\text { CENTURY model description } \\
\text { (Metherell et al. 1993). }\end{array}$ \\
\hline Residue C:N & $C N_{\text {residue }}$ & 196 & $\mathrm{gC} / \mathrm{gN}$ & & $\checkmark$ & $\checkmark$ & $\begin{array}{l}\text { Carbon to nitrogen ratio in crop } \\
\text { residue. In (Elias et al. 1998) this is } \\
\text { approximately four times the ratio of } \\
\text { the harvested crop. }\end{array}$ \\
\hline Maximum yield & $Y_{\max }$ & 6,590 & $\mathrm{~kg} / \mathrm{ha}$ & LSMS $^{\prime}$ & & $\checkmark$ & $\begin{array}{l}95^{\text {th }} \text { percentile maize yield over } \\
\text { Ethiopia in } 2011,2013 \text {, and } 2015\end{array}$ \\
\hline $\begin{array}{l}\text { Climate upper } \\
\text { threshold }\end{array}$ & $C^{\text {upper }}$ & 0.8 & - & $\begin{array}{l}\text { (Methere } \\
\text { ll et al. } \\
\text { 1993) }\end{array}$ & & $\checkmark$ & $\begin{array}{l}\text { Climate condition above which crop } \\
\text { yields plateau }\end{array}$ \\
\hline $\begin{array}{l}\text { Climate lower } \\
\text { threshold (low } \\
\text { SOM) }\end{array}$ & $C_{\text {low }}^{\text {lower }}$ & 0.3 & - & & $\checkmark$ & $\checkmark$ & $\begin{array}{l}\text { Climate condition below which crop } \\
\text { failure occurs with SOM is zero }\end{array}$ \\
\hline $\begin{array}{l}\text { Climate lower } \\
\text { threshold (high } \\
\text { SOM) }\end{array}$ & $C_{\text {high }}^{\text {lower }}$ & 0 & - & & & & $\begin{array}{l}\text { Climate condition below which crop } \\
\text { failure occurs with SOM is at its } \\
\text { maximum }\end{array}$ \\
\hline $\begin{array}{l}\text { Crop yield } \\
\text { random effect }\end{array}$ & $\sigma_{y}$ & 0.3 & - & & & $\checkmark$ & $\begin{array}{l}\text { Standard deviation of the crop yield } \\
\text { random effect, simulated as } \\
\sim N(1,0.3)\end{array}$ \\
\hline $\begin{array}{l}\text { Residue loss } \\
\text { factor }\end{array}$ & $l_{\text {residue }}$ & 10 & $\%$ & $\begin{array}{l}\text { (Assefa } \\
\text { et al. } \\
\text { 2013) }\end{array}$ & & & $\begin{array}{l}\text { Percentage of crop residues not } \\
\text { returned to the soil or fed to livestock }\end{array}$ \\
\hline $\begin{array}{l}\text { Residue } \\
\text { multiplier }\end{array}$ & mult & 2 & - & $\begin{array}{l}\text { (Bogale } \\
\text { et al. } \\
2008 \text {, } \\
\text { Assefa et } \\
\text { al. 2013) }\end{array}$ & & & $\begin{array}{l}\text { Residue production per unit of } \\
\text { harvested crop. }\end{array}$ \\
\hline \multicolumn{8}{|l|}{ Soil } \\
\hline SOM & $k_{\text {slow }}$ & 2 & \%/year & (Schmidt & & $\checkmark$ & 50-year turnover time of bulk SOM \\
\hline $\begin{array}{l}\text { mineralization } \\
\text { rate }\end{array}$ & & & & $\begin{array}{l}\text { et al. } \\
\text { 2011) }\end{array}$ & & & \\
\hline $\begin{array}{l}\text { Applied organic } \\
\text { matter } \\
\text { mineralization } \\
\text { rate }\end{array}$ & $k_{\text {fast }}$ & 10 & \%/year & & $\checkmark$ & $\checkmark$ & $\begin{array}{l}\text { The percentage of applied organic } \\
\text { matter (manure and/or crop residues) } \\
\text { that mineralizes in the year of } \\
\text { application. }\end{array}$ \\
\hline Initial SOM & $S O M_{0}$ & 4,000 & kg N/ha & - & & $\checkmark$ & See text in section A1.3.3 \\
\hline Maximum SOM & $S O M_{\max }$ & 8,000 & $\mathrm{~kg} \mathrm{~N} / \mathrm{ha}$ & - & & $\checkmark$ & See text in section A1.3.3 \\
\hline $\begin{array}{l}\text { Maximum } \\
\text { leaching rate }\end{array}$ & $l_{N}^{\max }$ & 25 & $\%$ & $\begin{array}{l}\text { (Giller et } \\
\text { al. 1997, } \\
\text { Di and } \\
\text { Cameron } \\
\text { 2002) }\end{array}$ & $\checkmark$ & $\checkmark$ & $\begin{array}{l}\text { Rate of leaching of mineralized } \\
\text { organic matter when SOM is zero. }\end{array}$ \\
\hline
\end{tabular}




\begin{tabular}{|c|c|c|c|c|c|c|c|}
\hline Parameter & Symbol & Value & Unit & Source & $\begin{array}{l}\text { Uncer- } \\
\text { tain }^{+}\end{array}$ & $\begin{array}{l}\text { Sensit- } \\
\text { ivity } \\
\text { analysis }\end{array}$ & Description / notes \\
\hline $\begin{array}{l}\text { Minimum } \\
\text { leaching rate }\end{array}$ & $l_{N}^{\min }$ & 5 & $\%$ & $\begin{array}{l}\text { (Di and } \\
\text { Cameron } \\
\text { 2002) }\end{array}$ & & $\checkmark$ & $\begin{array}{l}\text { Rate of leaching of mineralized } \\
\text { organic matter when SOM is at its } \\
\text { maximum. }\end{array}$ \\
\hline \multicolumn{8}{|l|}{ Livestock } \\
\hline $\begin{array}{l}\text { Wealth:nitrogen } \\
\text { conversion }\end{array}$ & $W N_{\text {conv }}$ & 0.018 & $\begin{array}{l}\mathrm{kg} \\
\mathrm{N} / \text { year/bi } \\
\mathrm{rr}\end{array}$ & - & $\checkmark$ & $\checkmark$ & $\begin{array}{l}0.026 \mathrm{kgN} / \mathrm{year} / \mathrm{birr} \text { is the derived } \\
\text { value for comparison (see text in } \\
\text { section A1.3.3) }\end{array}$ \\
\hline $\begin{array}{l}\text { Percent crop } \\
\text { grazing }\end{array}$ & $c_{\text {residues }}$ & 52 & $\%$ & $\begin{array}{l}\text { (Keftasa } \\
\text { 1988, } \\
\text { Bediye et } \\
\text { al. 2001) }\end{array}$ & $\checkmark$ & $\checkmark$ & $\begin{array}{l}\text { Percentage of livestock food } \\
\text { requirements that come from crop } \\
\text { residues. The remainder comes from } \\
\text { a non-modeled external rangeland. }\end{array}$ \\
\hline $\begin{array}{l}\text { Consumption } \\
\text { requirement }\end{array}$ & $c f$ & 2,280 & $\begin{array}{l}\text { kg DM/ } \\
\text { TLU/ } \\
\text { year } 9\end{array}$ & $\begin{array}{l}\text { (Amsalu } \\
\text { and } \\
\text { Addisu } \\
\text { 2014) }\end{array}$ & & $\checkmark$ & $\begin{array}{l}\text { We assume all residues are dry } \\
\text { matter }\end{array}$ \\
\hline \multirow{2}{*}{\multicolumn{8}{|c|}{ Climate }} \\
\hline & & & & & & & \\
\hline \begin{tabular}{l|l} 
& Mean \\
\end{tabular} & $\mu_{c}$ & 0.5 & - & & & $\checkmark$ & \\
\hline $\begin{array}{l}\text { Standard } \\
\text { deviation }\end{array}$ & $\sigma_{c}$ & 0.2 & - & & & $\checkmark$ & \\
\hline & & & & & & & \\
\hline \multicolumn{8}{|l|}{$\begin{array}{l}\text { Adaptation option: } \\
\text { insurance }\end{array}$} \\
\hline \begin{tabular}{l|l} 
Climate \\
percentile
\end{tabular} & Ins $s_{\text {perc }}$ & 10 & $\%$ & & & & $\begin{array}{l}\text { Climate threshold (percentile of } \\
\text { cumulative distribution function) } \\
\text { below which an insurance payout is } \\
\text { received. }\end{array}$ \\
\hline $\begin{array}{l}\text { Payout } \\
\text { magnitude }\end{array}$ & Ins $s_{\text {payout }}$ & 1 & - & & & & $\begin{array}{l}\text { Insurance payout relative to the } \\
\text { expected yield. For example, if this is } \\
\text { 1, the insurance payout will equal the } \\
\text { income from an average year's yields } \\
\text { (assuming no nutrient limitations on } \\
\text { crop growth). }\end{array}$ \\
\hline Cost factor & Ins $s_{\text {cost }}$ & 1 & - & & & & $\begin{array}{l}\text { Fairness of insurance. A value of } 1 \\
\text { indicates an actuarially fair policy, } \\
\text { where the annual cost is equivalent to } \\
\text { the expected annual benefit. }\end{array}$ \\
\hline & & & & & & & \\
\hline \multicolumn{8}{|l|}{$\begin{array}{l}\text { Adaptation option: } \\
\text { cover crop }\end{array}$} \\
\hline \begin{tabular}{l|l} 
Nitrogen \\
fixation
\end{tabular} & $C C_{N f i x}$ & 95 & Kg N/ha & $\begin{array}{l}\text { (Büchi et } \\
\text { al. 2015, } \\
\text { Wittwer } \\
\text { et al. } \\
2017 \text {, } \\
\text { Couëdel } \\
\text { et al. } \\
\text { 2018) } \\
\end{array}$ & & & $\begin{array}{l}\text { Maximum value with no water } \\
\text { limitation. }\end{array}$ \\
\hline Cost factor & $C C_{\text {cost }}$ & 1 & - & & & & $\begin{array}{l}\text { Annual cost of cover cropping } \\
\text { relative to the cost of insurance. }\end{array}$ \\
\hline \multicolumn{8}{|c|}{$\begin{array}{l}\text { † The values displayed for the uncertain parameters were } \\
\text { f http://www.fao.org/giews/food-prices/tool/public/ } \\
\text { § CSA = Ethiopian Central Statistical Agency. Source = } \\
\text { | LSMS = Living Standards Measurement Study } \\
\text { 9 DM = dry matter, TLU = tropical livestock unit }\end{array}$} \\
\hline
\end{tabular}




\section{A1.3.4 Sub-models}

\section{A1.3.4.1 Soil nutrients}

The model contains two main pools of soil nutrients: organic and mineralized. The states of these pools are measured in $\mathrm{kg} \mathrm{N} / \mathrm{ha}$. Each year, a portion of the organic pool of nutrients (SOM) mineralizes according to a linear decay process. Organic nutrients applied to the soil (manure and crop residues; $N_{\text {added }}$ ) also are partially mineralized in the year of application (with a linear rate constant larger than that of the SOM), with the non-mineralized component added to the bulk SOM. We do not differentiate between the addition of "organic matter" and "nitrogen" and use a single variable to retain simplicity.

$$
\begin{aligned}
& N_{\text {mineralized }}^{\text {SOM }}=k_{\text {slow }} S_{\text {mine }} \\
& N_{\text {mineralized }}^{\text {added }}=k_{\text {fast }} N_{\text {added }} \\
& N_{\text {mineralized }}^{\text {total }}=N_{\text {mineralized }}^{\text {SOM }}+N_{\text {mineralized }}^{\text {added }} \\
& S O M_{t+1}=\left(S O M_{t}-N_{\text {mineralized }}^{\text {SOM }}\right)+\left(N_{\text {added }}-N_{\text {mineralized }}^{\text {added }}\right)
\end{aligned}
$$

After mineralization, a percentage of the mineralized nutrients is leached from the system. Higher levels of SOM contribute to lower leaching rates (Drinkwater et al. 1998). Specifically, we assume a maximum leaching rate with no SOM $\left(l_{N}^{\max }\right)$ and a minimum leaching rate when SOM is at its maximum $\left(l_{N}^{\min }\right)$, with a linear interpolation between these two points (see Table A1.1 for parameter values).

Mineral $\mathrm{N}$ that remains after leaching is assumed to be fully available to the crop. If this is higher than the crop's $\mathrm{N}$ requirements, any excess mineral $\mathrm{N}$ is assumed to be lost from the system via leaching (i.e., the mineral nutrient pool is reset each year).

This nutrient balance is partial and we do not model soil erosion (Cobo et al. 2010), yet the loss pathways that we include represent the largest magnitude pathways in mixed cropping-livestock systems (Tittonell et al. 2006). However, in its stylization, our representation of soil nutrient dynamics contains a number of simplifying assumptions, namely: (1) no endogenous or dynamic representation of $\mathrm{C}: \mathrm{N}$ ratios, (2) a single soil layer, (3) a single pool of organic nutrients with a single mineralization rate, (4) no explicit modeling of soil microbial biomass or other labile SOM pools, (5) no climate dependence in nutrient mineralization or leaching, (6) no nutrient dependence (e.g., N-limitations) in mineralization, (7) no differentiation between ammonium and nitrate as forms of inorganic $\mathrm{N}$, and (8) no atmospheric losses of $\mathrm{N}$ through denitrification. Despite these assumptions, we believe that our representation provides a reasonable first-level approximation of more complicated soil dynamics and requires far less parameterization. 


\section{A1.3.4.2 Climate}

Climate is represented through a single value, which is drawn each year from a normal distribution (parameters in Table A1.1) that is bounded between 0 and 1 . This value does not represent a specific physical climate characteristic (e.g., rainfall), but a stylized notion of the "climate condition". Under baseline conditions, the simulated climate values interact with the model solely through crop yields. Under the insurance scenario, payouts are received in years in which the climate condition is below the insurance index value, which is defined as some percentile of the cumulative distribution of the climate condition (i.e., a 10\% index represents the $10^{\text {th }}$ percentile of the cumulative distribution). With cover cropping, the climate condition also affects cover crop nitrogen fixation. The climate value is qualitatively similar to the outputs of process-based methods that calculate ratios of actual evapotranspiration to potential evapotranspiration (e.g., applications of the FAO crop water requirements methodology (FAO 1984, Allen et al. 1998, Block et al. 2008) and the CENTURY model (Metherell et al. 1993)), but requires far less parameterization.

\section{A1.3.4.3 Crop yields}

Crop yields can be reduced from a maximum potential value $\left(Y_{\max }\right)$ through water and/or nutrient limitations (Tittonell and Giller 2013). First, we calculate a water factor, $C_{\text {water }}$, with $0 \leq C_{\text {water }} \leq 1$. It is assumed that (see Figure A1.2): (1) if the climate value is greater than $C^{\text {upper }}$ (0.8 in the parameterized model), then $C_{\text {water }}=1$; (2) there is a critical climate value $(\geq$ 0 ) at which $C_{\text {water }}=0$; (3) higher levels of SOM lead to higher drought tolerance and hence a lower critical climate value; and (4) $C_{\text {water }}$ scales linearly between the critical value and $C^{\text {upper }}$. The maximum water-constrained yield $\left(Y_{w}\right)$ is then assumed to be:

$$
Y_{w}=C_{\text {water }} * Y_{\max }
$$

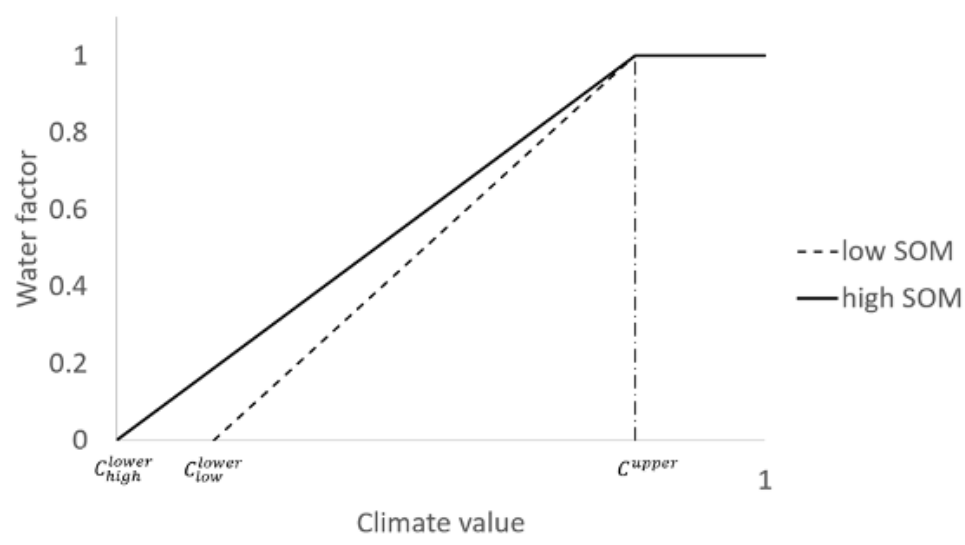

Figure A1.2: Effect of climate on crop yields. 
Second, we determine the maximum attainable nutrient-constrained crop yield $\left(Y_{N}\right)$ given the available mineral $\mathrm{N}$ in the soil $\left(N_{\text {mineralized }}^{\text {total }}\right)$ :

$$
Y_{N}=\frac{N_{\text {mineralized }}^{\text {total }}}{\frac{1}{C N_{\text {crop }}}+\frac{\text { mult }}{C N_{\text {residue }}}}
$$

This represents a partitioning of the $N_{\text {mineralized }}^{\text {total }}$ between the $\mathrm{N}$ in the harvested crop (adjusted by $C N_{\text {crop }}$ ) and the crop residues (adjusted by $C N_{\text {residue }}$ and multiplied by mult). The actual yield $\left(Y^{o b s}\right)$ is then calculated as

$$
Y^{o b s}=\min \left(\mathrm{Y}_{\mathrm{w}}, Y_{N}\right) * \varepsilon
$$

where $\varepsilon \sim N\left(1, \sigma_{y}{ }^{2}\right)$ is a household-level stochastic effect with $\sigma_{y}$ given in Table A1.1.

In this stylized crop yield model, we omit or simplify several processes that are included in more detailed process-based crop yield models, for example: (1) our one-dimensional representation of the effects of climate proxies any non-linearities in relationships between climate and yield as well as potential interactions between rainfall and temperature; (2) we do not model solar irradiation and growth of leaf area; and (3) we do not model the partitioning of growth between above- and below-ground biomass. Given the modular nature of our yield model, additional reduction factors could be added (e.g., see (Schreinemachers et al. 2007)) or more sophisticated process-based calculations could replace the existing calculations of water and nutrient limitations. However, this increased complication would require a greater amount of data and calibration, as well as reduce transparency in how specific inputs and structures mechanistically influence yields and the broader model dynamics.

\section{A1.3.4.4 Cover crop $N_{2}$ fixation}

As with vegetable crops, cover crops' biomass generation, and thereby their soil organic matter contributions, is also constrained by rainfall (Ewansiha and Singh 2006). We assume that the $\mathrm{N}$ fixed by the cover crop follows the same water response function as vegetable crop yields (i.e., Figure A1.2). Thus, in a year with no rainfall, no $\mathrm{N}$ is fixed. We set the default upper bound on $\mathrm{N}_{2}$ fixation as $95 \mathrm{~kg} \mathrm{~N} / \mathrm{ha}$ (Figure A1.3). 


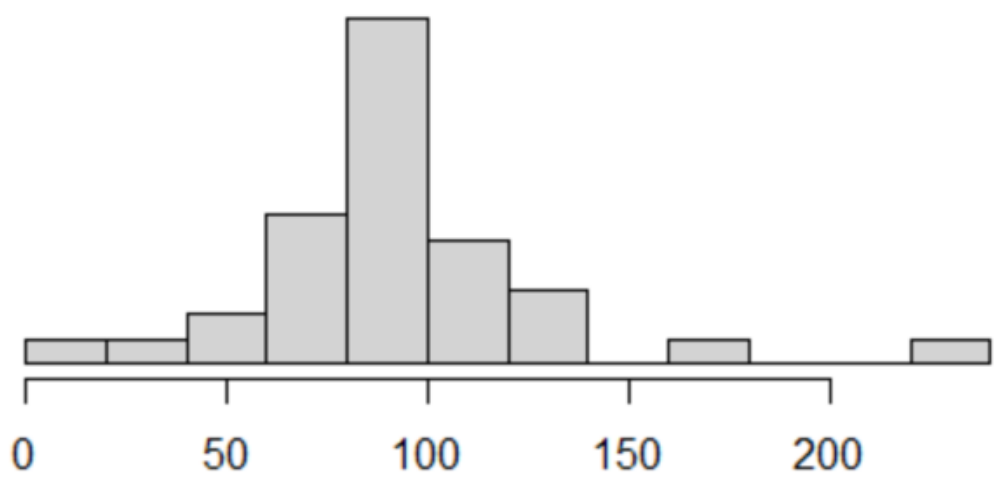

Figure A1.3: Distribution of cover crop N fixation (kg N/ha) in temperate climates reported in Badgley et al. (2007). The median value is $95 \mathrm{~kg} \mathrm{~N} / \mathrm{ha}$.

\section{A1.3.5 Pattern-oriented modeling (POM)}

\section{A1.3.5.1 Description}

We use latin hypercube sampling to generate 100,000 potential parameter sets, where each parameter is drawn uniformly from the ranges in Table A1.2. For each potential parameterization we run the model 10 times (to encompass climate variability) for a population of 100 households (to encompass variability induced by the random yield effect) for a period of 100 years. We choose only 10 model replications here due to computational reasons.

We assess whether each simulation generates a set of qualitative "patterns" (Table A1.3). These patterns collectively represent desired model behavior under baseline simulation conditions. To evaluate a potential parameter set we: (1) measure which patterns are generated in each simulation, (2) calculate the probability that each pattern is generated over the 10 replications, and (3) sum these averages over all patterns.

Table A1.2: Parameters included in the POM calibration

\begin{tabular}{|l|l|l|l|l|l|}
\hline & Parameter & Symbol & Minimum & Maximum & Notes \\
\hline 1 & Households: initial wealth & $W_{o}$ & 5,000 & 50,000 & \\
\hline 2 & Households: annual cash requirement & $C R$ & 5,000 & 30,000 & $\begin{array}{l}\text { Median annual expenditure in 2015 } \\
\text { LSMS is 17,261 birr }\end{array}$ \\
\hline 3 & Yields: climate lower threshold (low SOM) & $C_{\text {lower }}^{\text {lower }}$ & 0 & 0.5 & \\
\hline 4 & Yields: residue C:N & $C N_{\text {residue }}$ & 25 & 200 & Bounding the crop C:N ratio \\
\hline 5 & Livestock: percent crop grazing & $C_{\text {residues }}$ & 0.5 & 1 & $\begin{array}{l}\text { Livestock are often grazed primarily } \\
\text { on crop residue (e.g., (Keftasa 1988, } \\
\text { Bediye et al. 2001)) }\end{array}$ \\
\hline 6 & Livestock: wealth:nitrogen conversion & $W N_{\text {conv }}$ & 0.01 & 0.05 & $\begin{array}{l}\text { Bounding the empirically-derived } \\
\text { value }\end{array}$ \\
\hline 7 & $\begin{array}{l}\text { Soil: applied organic matter mineralization } \\
\text { rate }\end{array}$ & $k_{f a s t}$ & 0.05 & 0.95 & $\begin{array}{l}\text { Must be faster than the SOM } \\
\text { mineralization }\end{array}$ \\
\hline 8 & Soil: maximum leaching rate & $l_{N}^{\text {max }}$ & 0.05 & 0.95 & \\
\hline
\end{tabular}


Table A1.3: Patterns used for the POM calibration

\begin{tabular}{|l|l|l|}
\hline & Pattern & Requirements \\
\hline 1 & $\begin{array}{l}\text { Divergent household } \\
\text { wealth trajectories }\end{array}$ & $\begin{array}{l}\text { (a) All land-rich households finish the simulation with positive wealth AND } \\
\text { (b) All land-poor households finish the simulation with no wealth AND } \\
\text { (c) 20\%-80\% of the middle households finish the simulation with positive wealth. }\end{array}$ \\
\hline 2 & $\begin{array}{l}\text { Households can } \\
\text { recover from shocks }\end{array}$ & $\begin{array}{l}\text { There is at least one middle household that: } \\
\text { (a) Has no wealth at some point during the simulation AND } \\
\text { (b) Has positive wealth at the end of the simulation. }\end{array}$ \\
\hline 3 & $\begin{array}{l}\text { No saturation of } \\
\text { SOM }\end{array}$ & $\begin{array}{l}\text { There are no households consistently at the maximum level of SOM throughout the } \\
\text { last 10 years of the simulation. }\end{array}$ \\
\hline 4 & $\begin{array}{l}\text { Some households } \\
\text { can build SOM }\end{array}$ & $\begin{array}{l}\text { At least 10\% of households finish the simulation with a higher SOM than the initial } \\
\text { value }\end{array}$ \\
\hline
\end{tabular}

\section{A1.3.5.2 Results}

Of the 100,000 parameter sets, three generated on average 3.2 of the four patterns (Figure A1.4). We retained one of these parameterizations for the analysis presented in this paper.

Experimentation with the other two parameterizations yielded qualitatively similar results that do not affect the conclusions drawn in this paper.

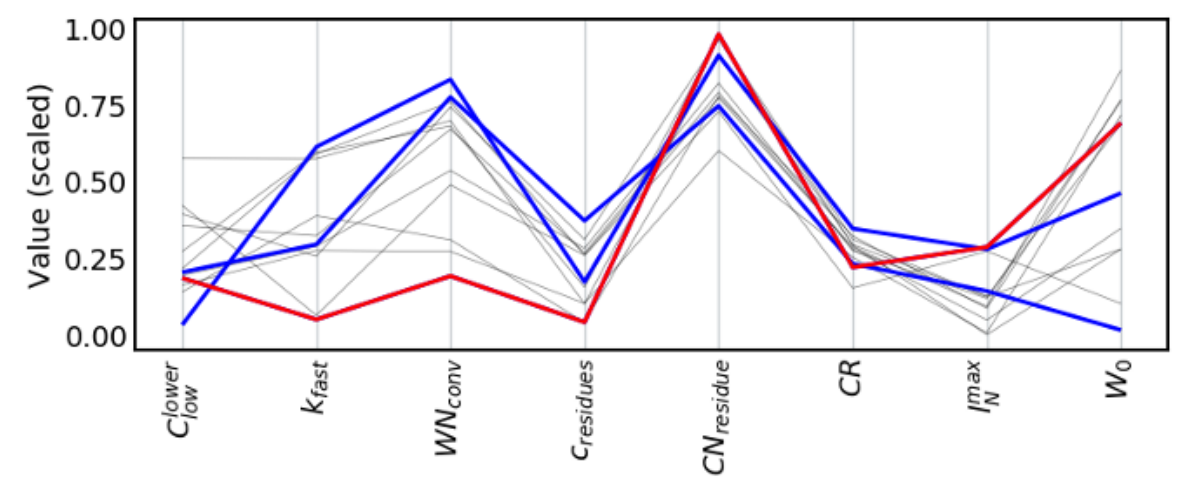

Figure A1.4: Scaled parameter values of the resultant POM parameterizations. The red line represents the selected parameterization. Blue lines represent the other parameterizations that reproduced the same number of patterns. Grey lines show parameterizations that were within $20 \%$ of the best.

\section{References}

Allen, R. G., L. S. Pereira, D. Raes, and M. Smith. 1998. FAO Irrigation and Drainage Paper. Food and Agriculture Organization.

Amsalu, T., and S. Addisu. 2014. Assessment of Grazing Land and Livestock Feed Balance in Gummara-Rib Watershed, Ethiopia. Current Agriculture Research Journal 2(2):114-122. 
Assefa, D., A. Nurfeta, and Others. 2013. Assessment of feed resource availability and livestock production constraints in selected Kebeles of Adami Tullu Jiddo Kombolcha District, Ethiopia. African Journal of Agricultural Research 8(29):4067-4073.

Badgley, C., J. Moghtader, E. Quintero, E. Zakem, M. Jahi Chappell, K. Avilés-Vázquez, A. Samulon, and I. Perfecto. 2007. Organic agriculture and the global food supply. Renewable Agriculture and Food Systems 22(2):86-108.

Bediye, S., G. Assefa, A. Tedla, and D. Fekadu. 2001. Present status and future direction in feed resources and nutrition research targeted for wheat based crop-livestock production system in Ethiopia. CIMMYT.

Bellemare, M. F., and C. B. Barrett. 2006. An Ordered Tobit Model of Market Participation: Evidence from Kenya and Ethiopia. American Journal of Agricultural Economics 88(2):324-337.

Bennett, A. J., G. D. Bending, D. Chandler, S. Hilton, and P. Mills. 2012. Meeting the demand for crop production: the challenge of yield decline in crops grown in short rotations. Biological Reviews 87(1):52-71.

Block, P. J., K. Strzepek, M. W. Rosegrant, and X. Diao. 2008. Impacts of considering climate variability on investment decisions in Ethiopia. Agricultural Economics 39(2):171-181.

Bogale, S., S. Melaku, and A. Yami. 2008. Matching Livestock Systems with Available Feed Resources in the Bale Highlands of Ethiopia. Outlook on Agriculture 37(2):105-110.

Bommarco, R., D. Kleijn, and S. G. Potts. 2013. Ecological intensification: harnessing ecosystem services for food security. Trends in Ecology \& Evolution 28(4):230-238.

Brisson, N., C. Gary, E. Justes, R. Roche, B. Mary, D. Ripoche, D. Zimmer, J. Sierra, P. Bertuzzi, P. Burger, F. Bussière, Y. M. Cabidoche, P. Cellier, P. Debaeke, J. P. Gaudillère, C. Hénault, F. Maraux, B. Seguin, and H. Sinoquet. 2003. An overview of the crop model stics. European Journal of Agronomy 18(3):309-332.

Büchi, L., C.-A. Gebhard, F. Liebisch, S. Sinaj, H. Ramseier, and R. Charles. 2015. Accumulation of biologically fixed nitrogen by legumes cultivated as cover crops in Switzerland. Plant and Soil 393(1):163-175.

Cobo, J. G., G. Dercon, and G. Cadisch. 2010. Nutrient balances in African land use systems across different spatial scales: A review of approaches, challenges and progress. Agriculture, Ecosystems \& Environment 136(1):1-15.

Couëdel, A., L. Alletto, H. Tribouillois, and É. Justes. 2018. Cover crop crucifer-legume mixtures provide effective nitrate catch crop and nitrogen green manure ecosystem services. Agriculture, Ecosystems \& Environment 254:50-59.

Di, H. J., and K. C. Cameron. 2002. Nitrate leaching in temperate agroecosystems: sources, factors and mitigating strategies. Nutrient Cycling in Agroecosystems 64(3):237-256.

Drinkwater, L. E., P. Wagoner, and M. Sarrantonio. 1998. Legume-based cropping systems have reduced carbon and nitrogen losses. Nature 396(6708):262-265.

Elias, E., S. Morse, and D. G. R. Belshaw. 1998. Nitrogen and phosphorus balances of Kindo Koisha farms in southern Ethiopia. Agriculture, Ecosystems \& Environment 71(1):93113. 
Ewansiha, S. U., and B. B. Singh. 2006. Relative drought tolerance of important herbaceous legumes and cereals in the moist and semi-arid regions of West Africa. Journal of Food Agriculture and.

FAO. 1984. Yield Response to Water. FAO Irrigation and Drainage Paper No. 33. Food and Agriculture Organization of the United Nations.

Ferreira, I. E. P., S. S. Zocchi, and D. Baron. 2017. Reconciling the Mitscherlich's law of diminishing returns with Liebig's law of the minimum. Some results on crop modeling. Mathematical Biosciences 293:29-37.

Giller, K. E., G. Cadisch, C. Ehaliotis, E. Adams, W. D. Sakala, and P. L. Mafongoya. 1997. Building Soil Nitrogen Capital in Africa. Pages 151-192 Replenishing Soil Fertility in Africa. Soil Science Society of America and American Society of Agronomy, Madison, WI.

Grillot, M., F. Guerrin, B. Gaudou, D. Masse, and J. Vayssières. 2018. Multi-level analysis of nutrient cycling within agro-sylvo-pastoral landscapes in West Africa using an agentbased model. Environmental Modelling \& Software 107:267-280.

Jones, J. W., G. Hoogenboom, C. H. Porter, K. J. Boote, W. D. Batchelor, L. A. Hunt, P. W. Wilkens, U. Singh, A. J. Gijsman, and J. T. Ritchie. 2003. The DSSAT cropping system model. European Journal of Agronomy 18(3):235-265.

Keating, B. A., P. S. Carberry, G. L. Hammer, M. E. Probert, M. J. Robertson, D. Holzworth, N. I. Huth, J. N. G. Hargreaves, H. Meinke, Z. Hochman, G. McLean, K. Verburg, V. Snow, J. P. Dimes, M. Silburn, E. Wang, S. Brown, K. L. Bristow, S. Asseng, S. Chapman, R. L. McCown, D. M. Freebairn, and C. J. Smith. 2003. An overview of APSIM, a model designed for farming systems simulation. European Journal of Agronomy 18(3):267-288.

Keftasa, D. 1988. Role of crop residues as livestock feed in the Ethiopian highlands. Pages 430439 African Forage Plant Genetic Resources, Evaluation of Forage Germplasm and Extensive Livestock Production Systems. Proceedings of a Workshop Held in Arusha. cgspace.cgiar.org.

Lupwayi, N. Z., M. Girma, and I. Haque. 2000. Plant nutrient contents of cattle manures from small-scale farms and experimental stations in the Ethiopian highlands. Agriculture, Ecosystems \& Environment 78(1):57-63.

Manzoni, S., and A. Porporato. 2009. Soil carbon and nitrogen mineralization: Theory and models across scales. Soil Biology \& Biochemistry 41(7):1355-1379.

Metherell, A., L. Harding, C. V. Cole, and W. J. Parton. 1993. CENTURY Soil organic matter model environment: Technical documentation. Agroecosystem version 4.0.

Moyo, S., and F. J. C. Swanepoel. 2010. Multifunctionality of livestock in developing communities. The role of livestock in developing communities: Enhancing multifunctionality 3:69.

Newcombe, K. 1987. An economic justification for rural afforestation: The case of Ethiopia. The Annals of Regional Science 21(3):80-99.

Reeves, D. W. 1997. The role of soil organic matter in maintaining soil quality in continuous cropping systems. Soil and Tillage Research 43(1):131-167.

Schmidt, M. W. I., M. S. Torn, S. Abiven, T. Dittmar, G. Guggenberger, I. A. Janssens, M. Kleber, I. Kögel-Knabner, J. Lehmann, D. A. C. Manning, P. Nannipieri, D. P. Rasse, S. 
Weiner, and S. E. Trumbore. 2011. Persistence of soil organic matter as an ecosystem property. Nature 478(7367):49-56.

Schreinemachers, P., T. Berger, and J. B. Aune. 2007. Simulating soil fertility and poverty dynamics in Uganda: A bio-economic multi-agent systems approach. Ecological Economics 64(2):387-401.

Tittonell, P., and K. E. Giller. 2013. When yield gaps are poverty traps: The paradigm of ecological intensification in African smallholder agriculture. Field Crops Research 143:76-90.

Tittonell, P., P. A. Leffelaar, B. Vanlauwe, M. T. van Wijk, and K. E. Giller. 2006. Exploring diversity of crop and soil management within smallholder African farms: A dynamic model for simulation of $\mathrm{N}$ balances and use efficiencies at field scale. Agricultural Systems 91(1):71-101.

Valbuena, D., O. Erenstein, S. Homann-Kee Tui, T. Abdoulaye, L. Claessens, A. J. Duncan, B. Gérard, M. C. Rufino, N. Teufel, A. van Rooyen, and M. T. van Wijk. 2012. Conservation Agriculture in mixed crop-livestock systems: Scoping crop residue tradeoffs in Sub-Saharan Africa and South Asia. Field Crops Research 132:175-184.

Wittwer, R. A., B. Dorn, W. Jossi, and M. G. A. van der Heijden. 2017. Cover crops support ecological intensification of arable cropping systems. Scientific Reports 7:41911. 


\section{APPENDIX 2 Convergence analysis}

The goal of the convergence analysis was to estimate how many replications of the model are required to generate model outputs that are not significantly influenced by stochasticity within the model. We refer to this number of replications as $r^{*}$. In our case, the quantity of interest is $P(C C>I n s)^{\text {shock }}$. We expect that this probability will vary considerably with both $T_{\text {shock }}$ and $T_{\text {assess }}$. Hence, we choose $r^{*}=\max \left(r_{T_{\text {shock }}^{*}, T_{\text {assess }}}\right), \forall\left(T_{\text {shock }}, T_{\text {assess }}\right)$ over $T_{\text {shock }} \in$ $\{5,10,20\}$ and $T_{\text {assess }} \in\{1,3,5,7,9,11,13\}$.

Our approach for estimating each $r_{T_{\text {shock }}, T_{\text {assess }}}^{*}$ was as follows:

1. Run a large number of model replications (1000).

2. Assume the estimated $P(C C>I n s)^{\text {shock }}$ over these replications $\left(\widehat{X}_{1000}\right)$ is the "true" value.

3. For each $r \in\{1, \ldots, 1000\}$, calculate the absolute error (AE) from the true value. For example, $A E_{50}=\left|\hat{X}_{1000}-\hat{X}_{50}\right|$, where $\hat{X}_{50}$ represents $P(C C>\text { Ins })^{\text {shock }}$ calculated over the first 50 replications.

4. Choose $r^{*}$ as the number of replications at which the absolute error in the estimated probability falls below 5\%, i.e., $r^{*}=\operatorname{argmax}_{n}\left(A E_{n}>0.05\right)$.

The threshold of 5\% was chosen as we do not require highly precise estimates of $P(C C>\operatorname{Ins})$ for our assessment. We acknowledge that our approach is relatively ad-hoc and not formally statistically grounded. However, it captures the essence of what we desire: estimates of $P(C C>$ Ins) that are robust to within-model stochasticity. We considered using the approach presented in Abreu and Ralha (2018), but the coefficient of variation (i.e., the standard deviation of $P(C C>$ Ins $)$ divided by the mean $)$ is unstable with estimates near zero. Additionally, we considered the approach presented in Law (2008) (pg. 502), but because our model is not computationally intensive it was feasible to run a large number of simulations and calculate $\widehat{X}_{n} \forall n$ and we adopted the approach described above.

The results indicate that $r^{*}=188$ is sufficient (Figure A2.1). To be conservative, we run the model at least 300 times for all experiments. For some figures we used a higher number of replications to improve visual clarity. 


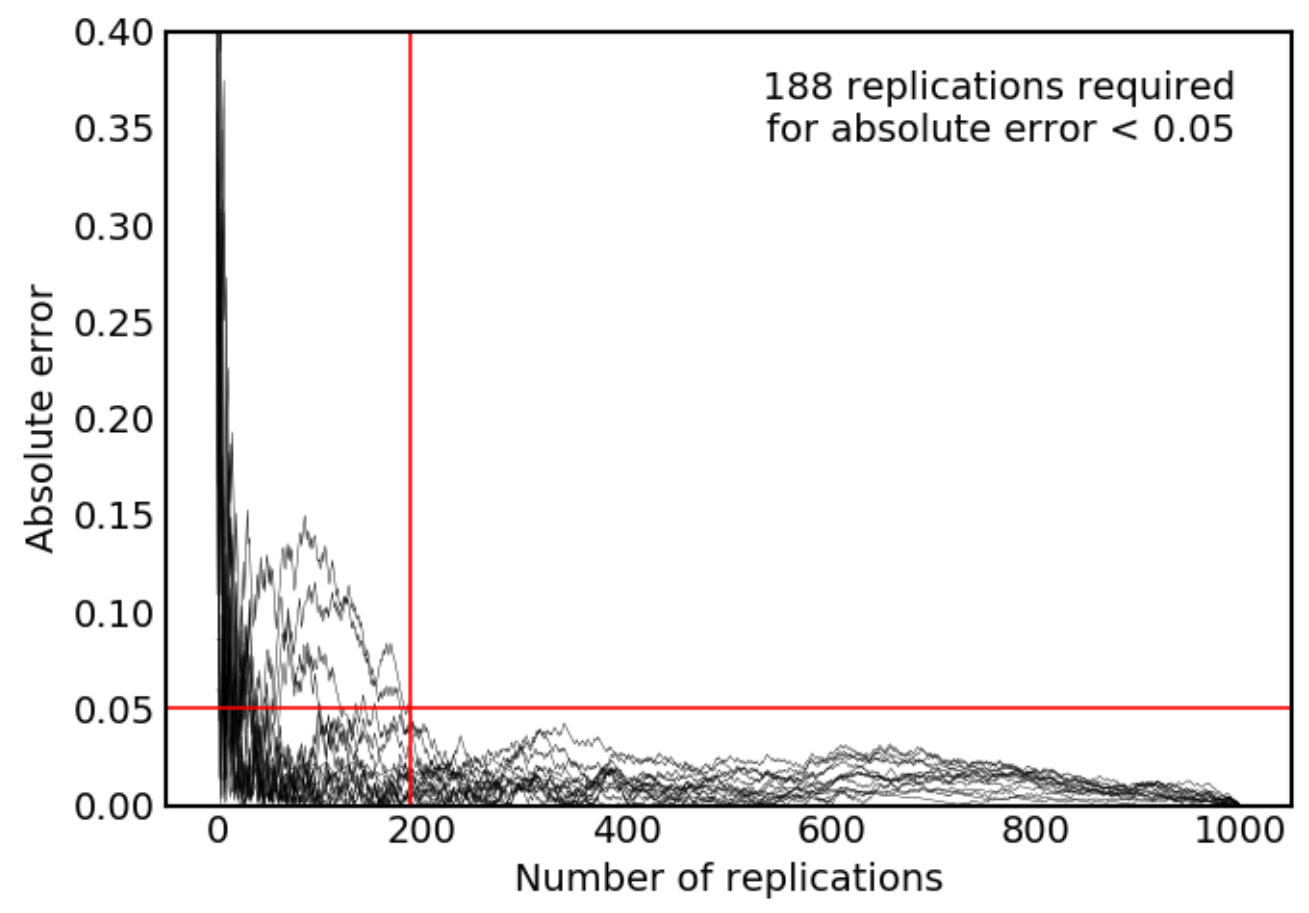

Figure A2.1: Absolute error in the estimate of $P(C C>$ ins $)$ as the number of model replications is increased. Each black line represents a unique $\left(T_{\text {shock }}, T_{\text {assess }}\right)$. The red lines show the point at which the absolute error falls below 0.05 for all ( $\left.T_{\text {shock }}, T_{\text {assess }}\right)$.

\section{References}

Abreu, C. G., and C. G. Ralha. 2018. An empirical workflow to integrate uncertainty and sensitivity analysis to evaluate agent-based simulation outputs. Environmental Modelling \& Software 107:281-297.

Law, A. M. 2008. Simulation modeling and analysis, Fourth Edition. McGraw-Hill New York. 


\section{APPENDIX 3 Sensitivity analysis methodology and additional results}

\section{A3.1 Parameter sampling}

We conducted a global sensitivity analysis on the majority of the parameters of the model (see Table A1.1 in the ODD+D description for the selected parameters). To generate perturbed parameter sets we employed the following procedure:

1. Generate a random deviation $a_{i}$ for each of the $P$ parameters $\left(\boldsymbol{a}=a_{1}, \ldots, a_{P}\right)$, allowing the deviation to be 30\% upwards or downwards: $\boldsymbol{a} \sim U(0.7,1.3)^{P}$

2. Perturb each parameter from its baseline value $X_{i}\left(\boldsymbol{X}=X_{1}, \ldots, X_{P}\right)$ by this simulated value, giving a perturbed parameter set: $\boldsymbol{S}_{r}^{\prime}=\boldsymbol{a} \boldsymbol{X}$

3. Repeat this procedure 10,000 times, giving $\boldsymbol{S}^{\prime}=\boldsymbol{S}_{1}^{\prime}, \ldots, \boldsymbol{S}_{10000}^{\prime}$. Here, we used latin hypercube sampling to increase the efficiency of the sampling of the parameter space.

\section{A3.2 Model evaluation}

For each set of perturbed parameters $\boldsymbol{S}_{r}^{\prime}$ calculate the Quantity of Interest $(Q o I)$, where the $Q o I$ takes two forms:

(a) $Q o I_{\text {shock }}$ represents $P(C C>\text { Ins })^{\text {shock }}$ in Experiment 1 (Table 1) with $T_{\text {assess }}=5$ and $T_{\text {shock }}=10$ and a $10 \%$ shock.

(b) $Q o I_{\text {pov }}$ represents $P(C C>\text { Ins })^{p o v}$ in Experiment 2 (Table 1) with $T_{\text {pov }}=50$.

The model evaluation procedure results in a "dataset" of sorts, where the independent variables are the parameters ( $\boldsymbol{S}^{\prime}$, with $P$ columns and 10,000 rows) and the dependent variable is the quantity of interest $\left(Q o I_{\text {pov }}\right.$ or $Q o I_{\text {shock }}$ of size 10,000).

\section{A3.3 Gradient-boosted regression forest}

The goal of the sensitivity analysis is to assess how changes in the parameters affect the QoI. Hence, we are interested in exploring the function $f$ in the relationship $Q o I=f\left(\boldsymbol{S}^{\prime}\right)$. This function may be non-linear. We trained a gradient-boosted regression forest (GBRF) to yield a non-parametric representation of $f$. A GBRF consists of a set of simple regression trees that are fit in a stagewise manner, with each successive tree being fit to the residuals of the previous. GBRFs originated in the machine learning community, and generally exhibit a high predictive performance (Elith et al. 2008). We do not discuss this method in detail here and refer interested readers to Elith et al. (2008).

\section{A3.4 Assessing variable influence}

We use partial dependence plots (PDPs) - a common visualization technique for non-parametric models - to visualize the associations between changes in each parameter and the QoI, as assessed by the GBRF. Each point $(x, y)$ on a partial dependence plot for parameter $p_{i}$ represents the average prediction made by the GBRF ( $y$ value) if every instance of $p_{i}$ is set to $x$, keeping all 
other parameters $\left(p_{-i}\right)$ at their original values. The slope of the PDP gives an indication of both the magnitude and direction of influence of the parameter on the QoI. A PDP for a linear regression model would show a straight line representing the regression coefficient $(\beta)$. To generate confidence bounds on our PDPs we bootstrap the "dataset" 100 times, each time retraining the GBRF and re-estimating the PDP.

\section{A3.5 Supplemental results}

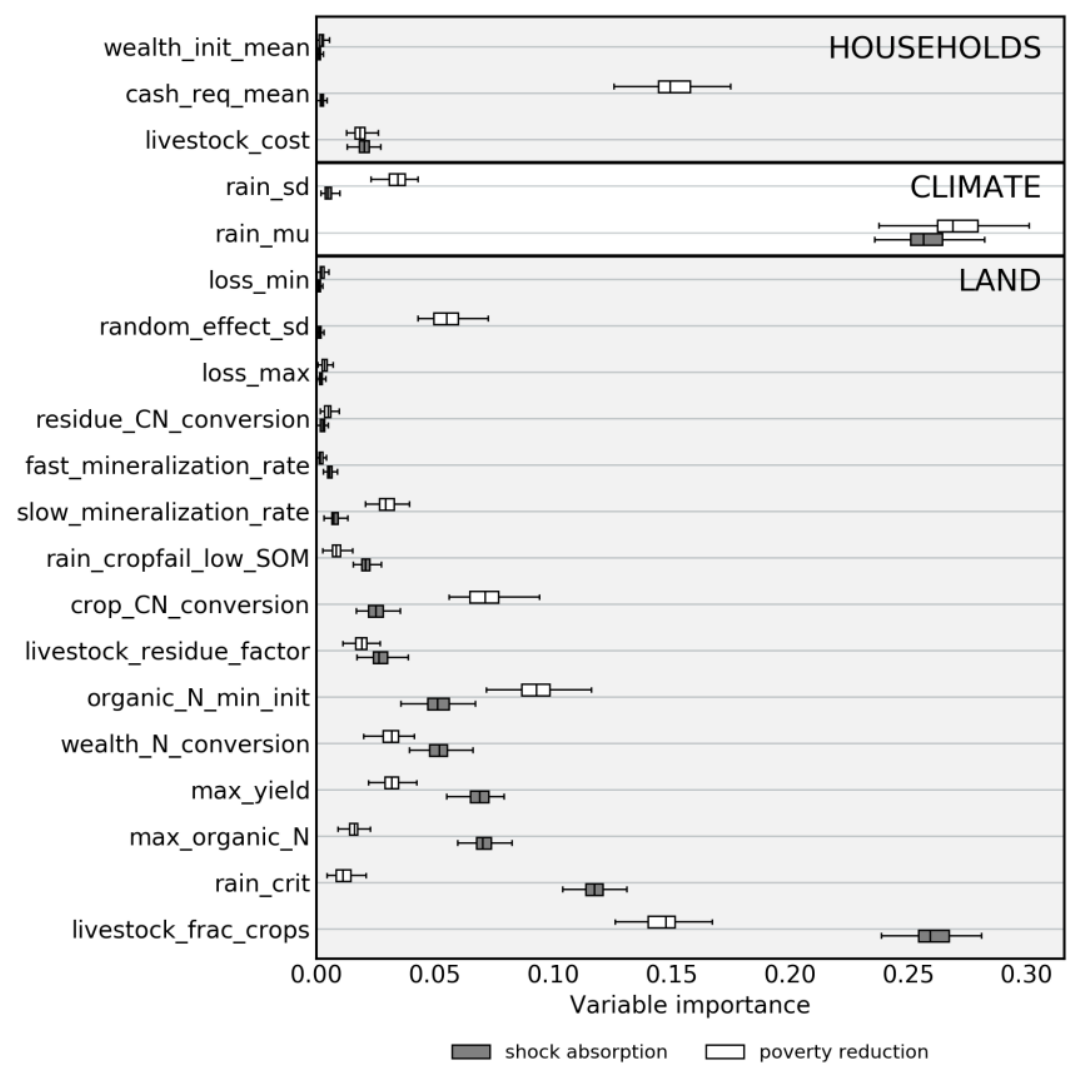

Figure A3.1: Importance of different model parameters in the sensitivity analysis, as calculated by the GBRF. The "variable importance" measure is calculated by scikit-learn in Python (Pedregosa et al. 2011) and is a measure of the amount of variance that each variable explains.

\section{References}

Elith, J., J. R. Leathwick, and T. Hastie. 2008. A working guide to boosted regression trees. Journal of Animal Ecology 77(4):802-813.

Pedregosa, F., G. Varoquaux, A. Gramfort, V. Michel, B. Thirion, O. Grisel, M. Blondel, P. Prettenhofer, R. Weiss, V. Dubourg, J. Vanderplas, A. Passos, D. Cournapeau, M. Brucher, M. Perrot, and E. Duchesnay. 2011. Scikit-learn: Machine Learning in Python. Journal of Machine Learning Research 12:2825-2830. 


\section{APPENDIX 4 Additional figures}

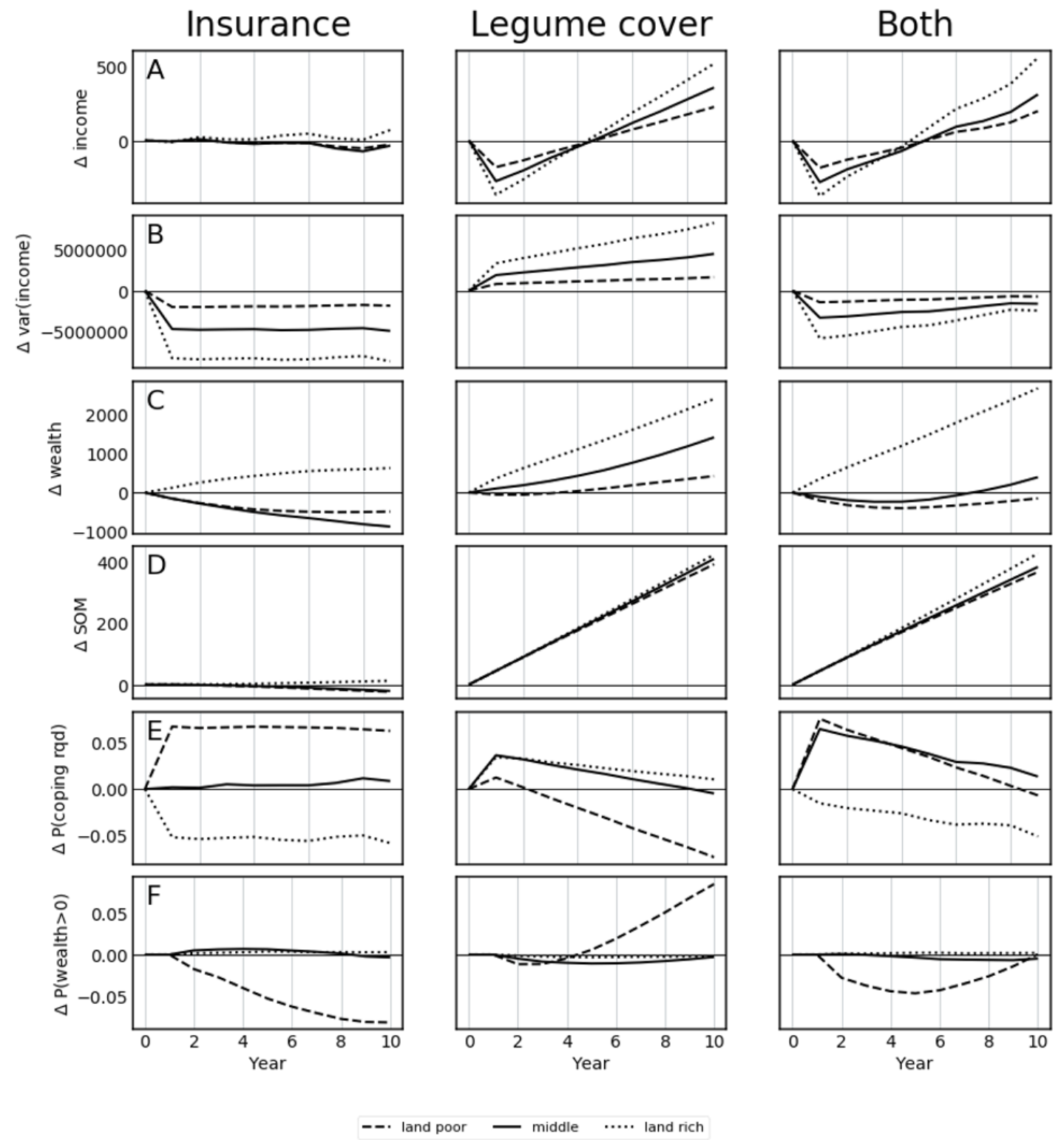

Figure A4.1: Effects of the strategies on various model characteristics relative to the baseline scenario for each type of household. In all cases, the horizontal line at zero represents no change relative to the baseline model conditions. "Change in P(coping rqd)" refers to change in the probability that a household must sell their livestock at each time step. "Change in $\mathrm{P}($ wealth $>0)$ " refers to change in the probability that a household has positive wealth (i.e., livestock) at each time step. 

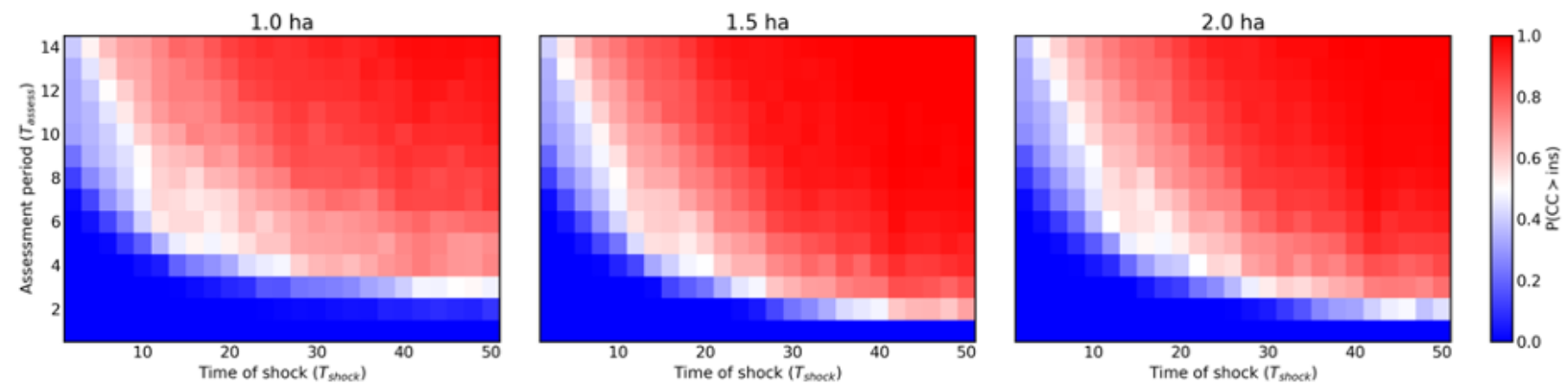

Figure A4.2: Comparison of insurance and cover cropping on $P(C C>I n s)^{\text {shock }}$ for the three types of household, which differ solely in their land holdings. Land-poor households have 1 ha of land, middle households have 1.5 ha, and land-rich households have 2 ha.
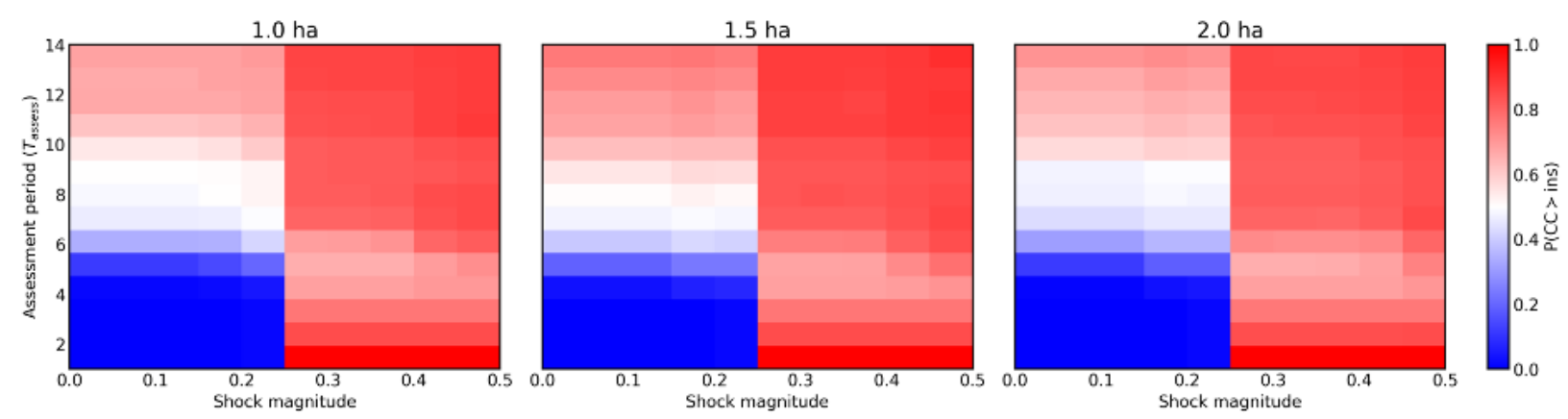

Figure A4.3: Comparison of insurance and cover cropping on shock absorption as the magnitude of the drought is varied, with $T_{\text {shock }}=10$. The vertical threshold at 0.25 represents the microinsurance climate index. 


\section{A: Insurance}
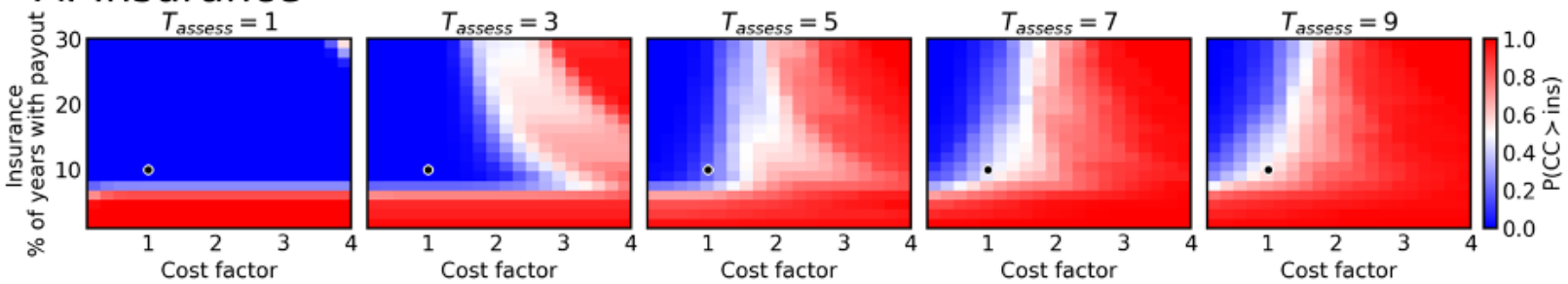

\section{B: Legume cover}
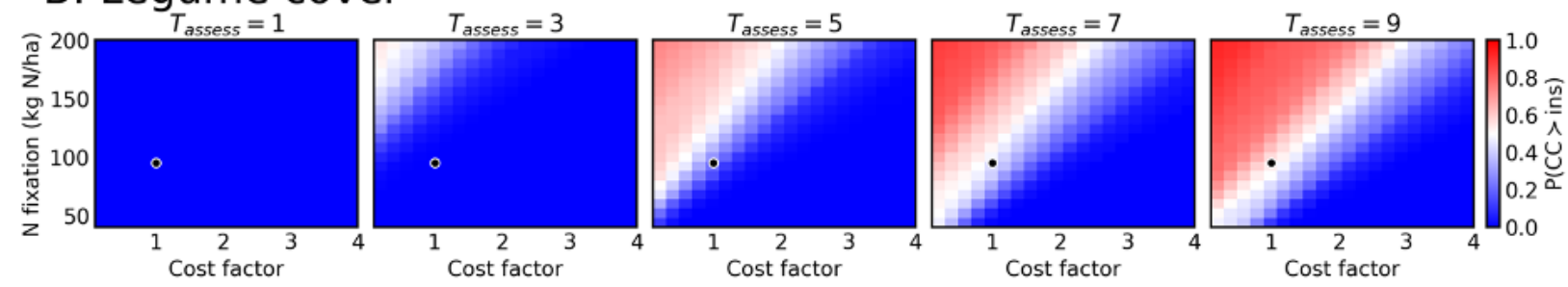

Figure A4.4: Influence of strategy characteristics on the shock absorption comparison. The black dots represent the baseline settings used in other experiments. In all cases, we simulated a 0.2 magnitude shock with $T_{\text {shock }}=10$ and averaged results over all household types. Results were qualitatively similar for each individual household type.
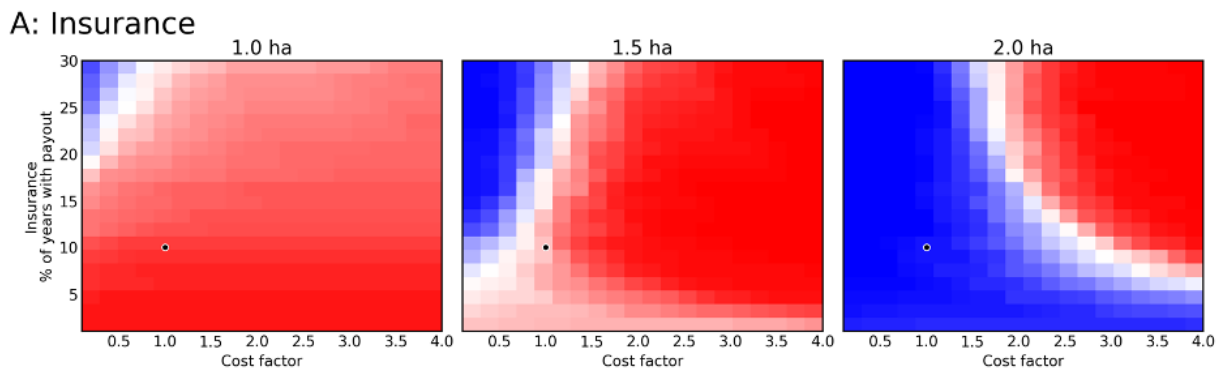

B: Legume cover

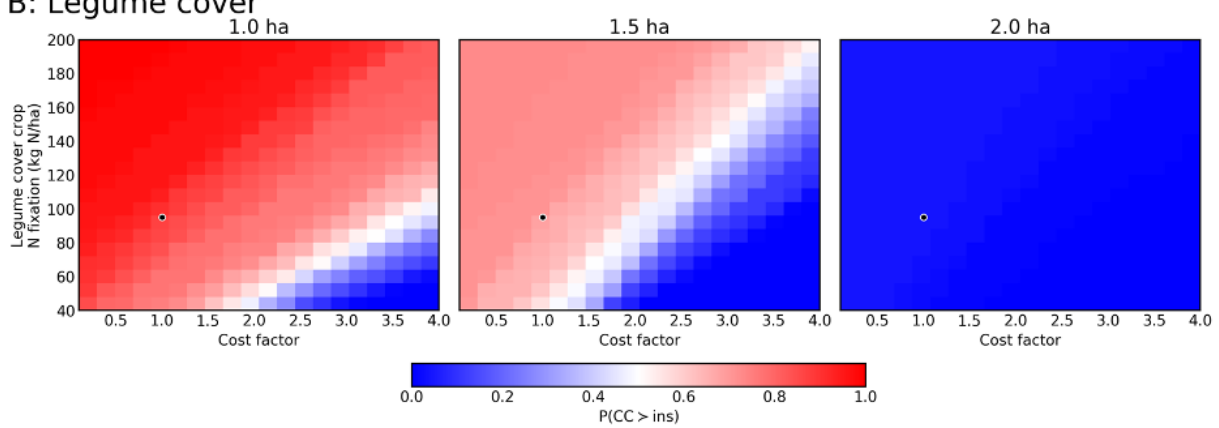

Figure A4.5: Influence of strategy characteristics on the poverty reduction assessment for different household types with $T_{d e v}=20$. Note that poverty reduction measures households that have lost all their wealth; since the land-rich households (2 ha) very rarely lose their wealth even under baseline conditions (Figure 5), the stark differences seen in this assessment (right-most plots) for these households are not meaningful. 

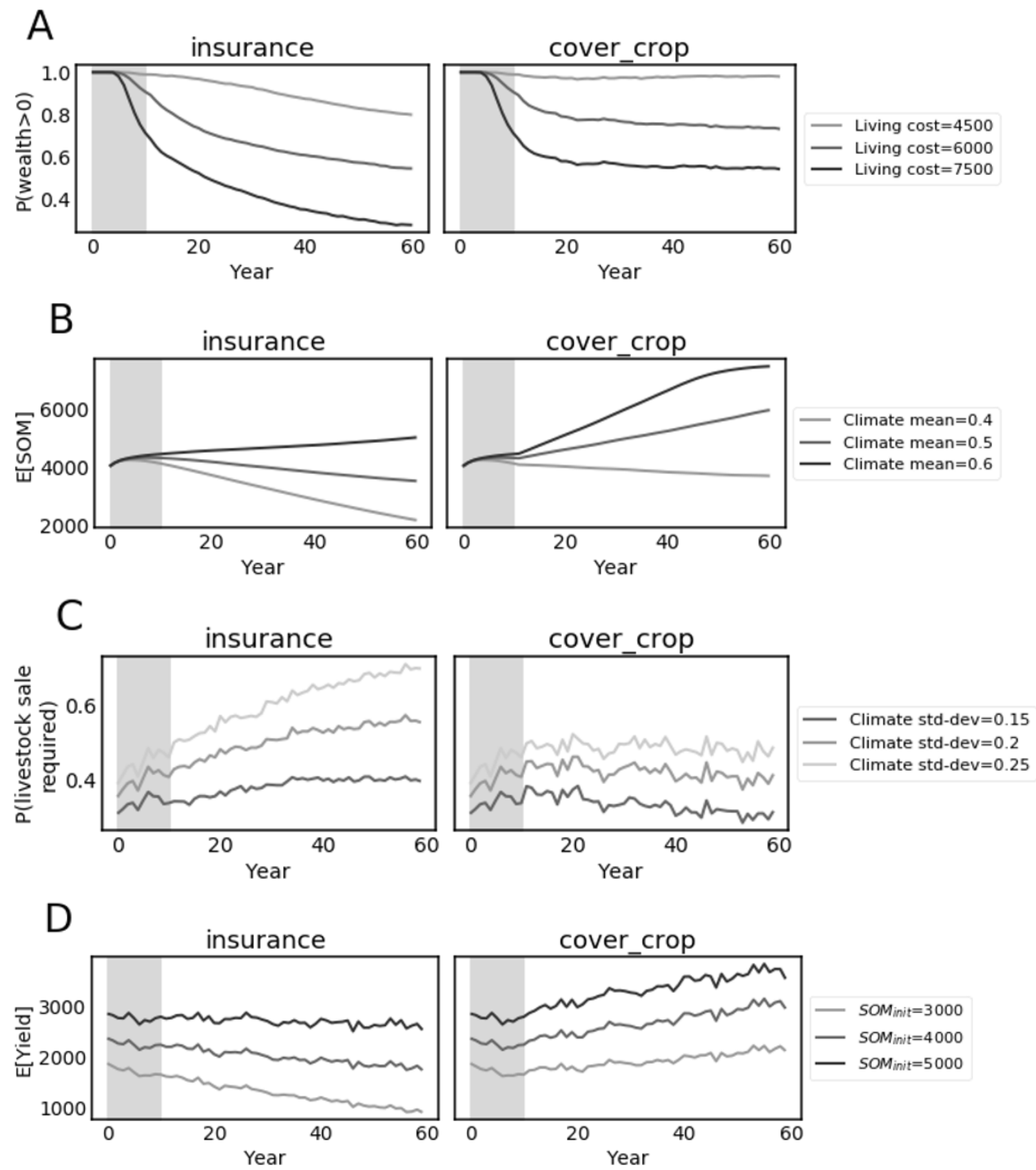

Figure A4.6: Evolution of model metrics under different parameter settings. Plotted values represent averages over all household types. "P(livestock sale required)" represents the probability that any livestock sale is required, independent of the number. 


\section{APPENDIX 5 Synergies}

The analysis in the main body of the article reveals a story of complementarity between microinsurance and cover cropping. Here, we examine whether the strategies, when implemented together, lead to synergistic effects. We conceptualize a synergy as a situation in which "the sum is greater than the parts". In this case, this represents:

$$
\text { Benefit }_{\text {both }}>\text { Benefit }_{C C}+\text { Benefit }_{\text {Ins }}
$$

where the "Benefit" is measured in the same way as shock absorption (Equation 1 in the main manuscript).

The results (Figure A5.1) reveal that the modeled strategies exhibit synergies with respect to shock absorption in the long-term. In the short term, however, the combined effect is less than the sum of its parts. This is mainly explained by cover cropping's short-term detriment to shock absorption while soil organic matter (SOM) is being built. The long-term synergy is not surprising, given the structure of the model; each strategy operates through distinct mechanisms: cover cropping through the building of SOM and microinsurance through income stabilization. Each of these mechanisms enables the wealth-SOM feedback loop, consequently contributing to higher income. Due to this feedback, the combined effect of the strategies is heightened, and therefore synergistic.

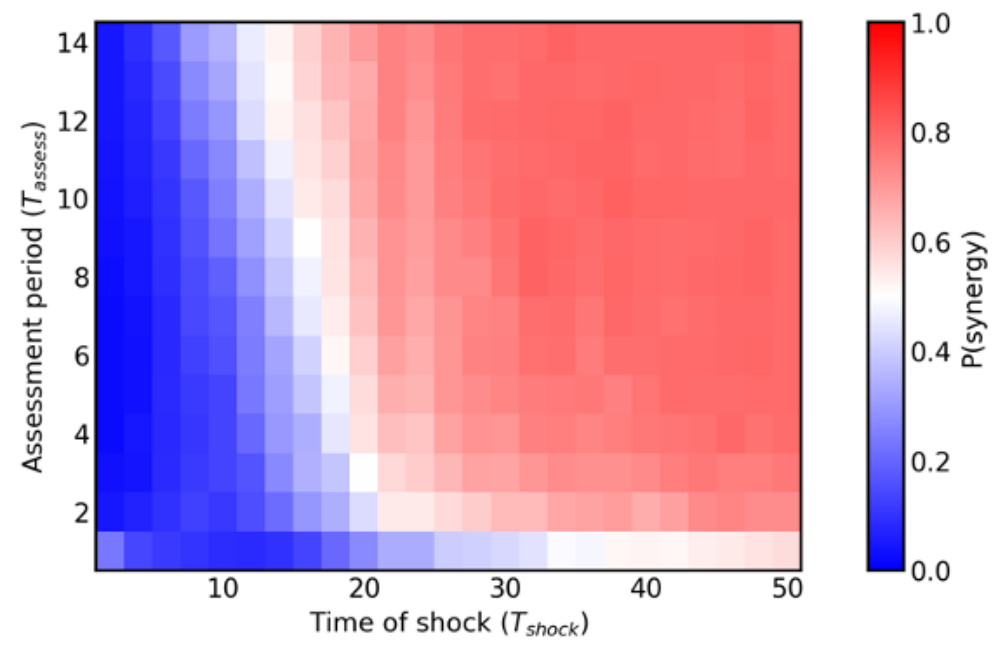

Figure A5.1: Probability that both strategies together provide larger benefits than the sum of both strategies separately. This represents the outcomes for a "middle" household and a 0.2 magnitude drought. 


\section{APPENDIX 6 Utility analysis}

The focus in the main body of the paper centered primarily around the two measures of resilience: shock absorption and poverty reduction. Our results showed that-predicated on the structure of the model and scenarios - cover cropping reduces poverty by increasing income over time, while microinsurance effectively buffers income in the wake of a drought. However, other economic indicators may be relevant for households that are not as vulnerable to poverty (i.e., land-rich in our analysis). In particular, risk-averse households may be interested in reducing income variability in addition to increasing mean income. Hence, microinsurance may provide benefit to these types of household that our resilience analysis does not identify.

To formalize this benefit, we calculated an expected risk-averse utility on income over time under each scenario. We used an exponential utility function of the form $1-\exp (-X / R)$, where $X$ represents income and $R$ represents the household's risk tolerance. Figure A6.1 shows that the utility of more risk-averse households (i.e., with lower risk tolerance) is more strongly benefited by insurance than cover cropping. Due to the delay in cover cropping's benefits on income, cover cropping leads to a short-term reduction in utility, which after 20-50 years increases to eventually exceed that of microinsurance. At lower levels of risk aversion (i.e., higher risk tolerance), the shape of the utility effects more closely mirrors that of expected income (Figure A4.1). Hence, by reducing income variability (specifically, the downside income risk), microinsurance may be a more promising strategy for risk-averse households that are not in poverty or whose crop yields are not highly nutrient limited.

When both strategies are implemented together, the long-run utility exceeds that of both strategies in isolation, demonstrating a complementary effect on utility. However, due to the short-term financial tradeoffs associated with cover cropping, the shorter-term utility of both options together is lower than with microinsurance. Nevertheless, particularly for a risk-averse household, at no point does the combined utility decrease below the baseline condition. This demonstrates that, from a utility perspective, the welfare impacts of the short-term losses associated with cover cropping may be offset by the risk reduction offered by microinsurance.
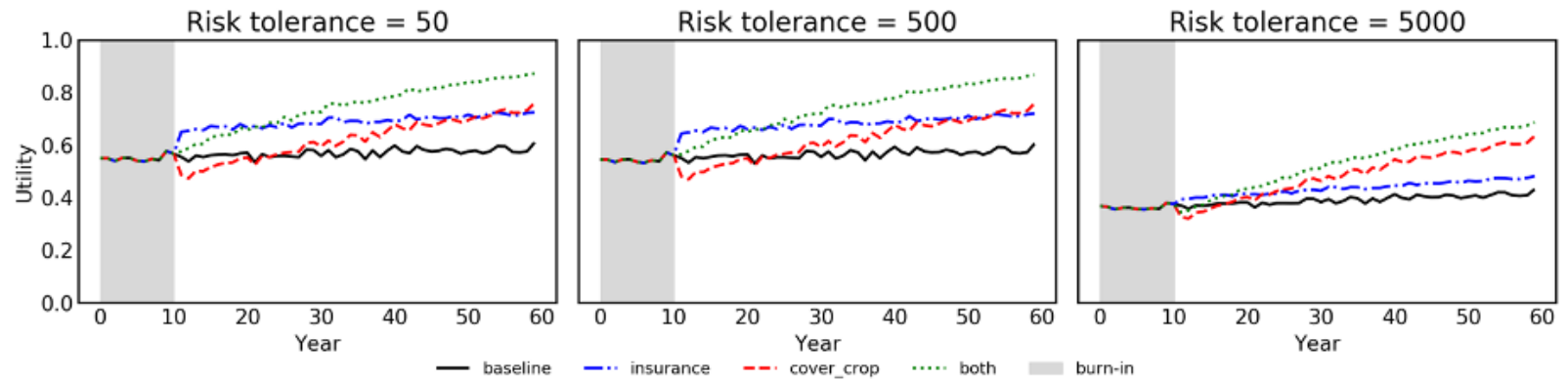

Figure A6.1: Expected utility over time for a land-rich household under three levels of risk tolerance. Higher risk tolerance corresponds to lower risk aversion. 


\section{APPENDIX 7 Effect of microinsurance climate index}

The microinsurance scheme is structured such that the insurance is "fair". For instance, if the insurance provides payouts in $5 \%$ of the years, the annual cost is $1 / 20^{\text {th }}$ of the payout. Similarly, if the insurance provides payouts in $20 \%$ of the years, the annual cost is $1 / 5^{\text {th }}$ of the payout. Thus, an insurance scheme with more frequent payouts entails higher premium costs. As a result, an insurance scheme that provides more regular payouts provides a lower net benefit to the household in a year in which the insurance is triggered. (Note that the strike rate affects the rainfall value at which the insurance is triggered.)

This characteristic results in a tradeoff in our model with respect to the microinsurance climate index (Figure A7.1). Here, "climate condition" represents the annual realization of climate. The probability of a given climate condition occurring is influenced by the climate distribution (i.e., climatic context; here $\sim N(0.5,0.2))$, but the outcomes in Figure A7.1 under a given climate condition depend only on the climate condition itself.

For example, under the most extreme plotted climate condition (0.05), an insurance payout is received for all insurance indexes (strike rates). This payout is the same for all insurance indexes (5\% insured, $10 \%$ insured, etc.). However, the cost of the premium is highest in the $30 \%$ insured case (i.e., 30\% of the payout). This high premium means that, despite the payout being received, the household receives a lower net benefit in this year. As a result, the probability with which it must sell livestock is higher (0.55) than under an insurance scheme that provides less regular payouts (e.g., 0.10 probability under the 5\% insurance index).

However, the higher insurance indexes (e.g., 30\% insured) also provide payouts under less extreme drought conditions. For example, when the climate condition is 0.4 , a payout is received under the 30\% insurance index but not under any of the other assessed indexes. As a result, the probability with which livestock selling is required is lowest for the $30 \%$ insurance index under this climate condition.

Together, this represents a tradeoff in which insurance that provides more regular payouts offers protection under moderate climate conditions at the expense of vulnerability under more severe climate conditions, whereas insurance that provides less regular payouts protects against the severe climate conditions at the expense of vulnerability under more moderate conditions. Depending on the distribution of the climate condition (here, $\sim N(0.5,0.2)$ truncated at 0 and 1 ), the net effect of this tradeoff will change as the probability of more and less extreme climate conditions shifts. In addition, farmer-level risk preferences may influence the aversion to different kinds of loss. Thus, the robust design of index-based microinsurance schemes in case study applications should consider the potential for this type of tradeoff. 


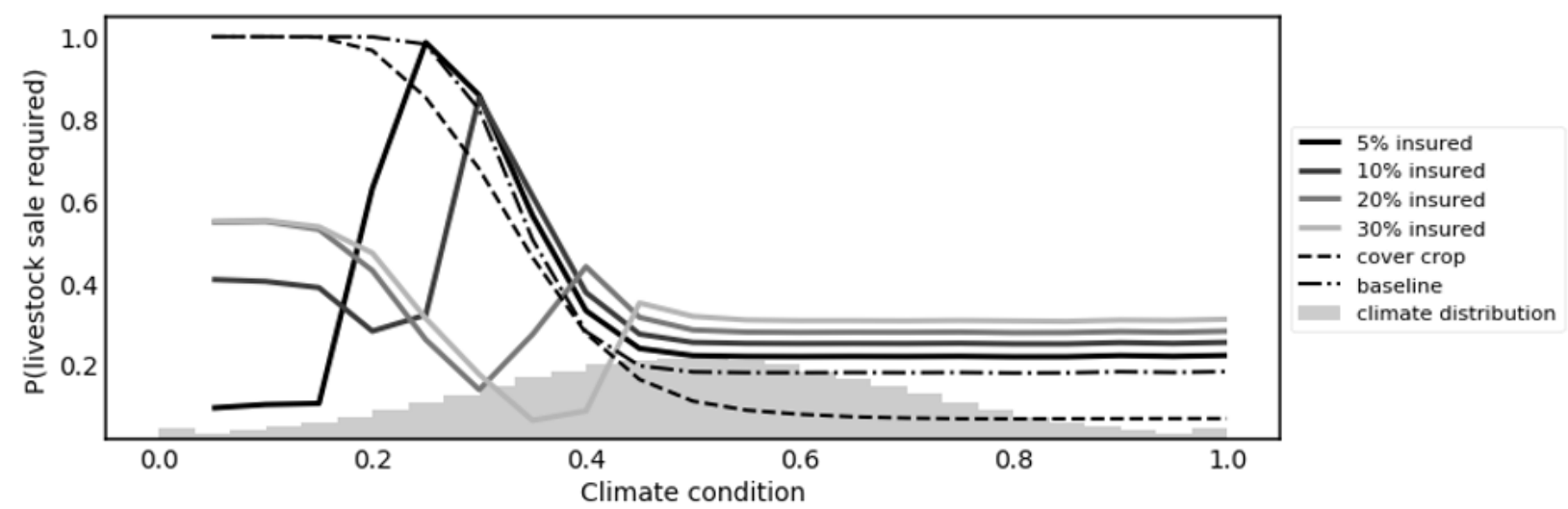

Figure A7.1: The probability that livestock selling as a coping measure is required as a function of the annual climate condition in a simulation under regular climate variability $(\sim N(\mu=$ $0.5, \sigma=0.2)$ ) and different insurance coverages. For example, a point $(0.4,0.7)$ represents a case in which during a year with a climate condition at 0.4 (affecting crop production - see section A1.3.4.2 in the ODD+D) there is a 70\% chance that the household's annual income is insufficient to satisfy their consumption and they must sell livestock resources. 5\% insured represents an index-based insurance in which a payment is received in $5 \%$ of years. This is for a land-poor household only. 